\title{
Article \\ New Ways to Measure Mechanical Losses by Motoring an ICE with Increased Cylinder Pressure
}

\author{
Radek Procházka *, Aleš Dittrich (D), Robert Voženílek and Stanislav Beroun \\ Department of Vehicles and Engines, Technical University of Liberec, Studentská 1402, \\ 46117 Liberec, Czech Republic; ales.dittrich@tul.cz (A.D.); robert.vozenilek@tul.cz (R.V.); \\ stanislav.beroun@tul.cz (S.B.) \\ * Correspondence: radek.prochazka@tul.cz; Tel.: +420-737-185-115
}

Citation: Procházka, R.; Dittrich, A.; Voženílek, R.; Beroun, S. New Ways to Measure Mechanical Losses by Motoring an ICE with Increased Cylinder Pressure. Appl. Sci. 2022, 12, 2155. https://doi.org/10.3390/ app12042155

Academic Editors: Michal Puškár and Georgios Karavalakis

Received: 12 December 2021 Accepted: 16 February 2022 Published: 18 February 2022

Publisher's Note: MDPI stays neutral with regard to jurisdictional claims in published maps and institutional affiliations.

Copyright: (C) 2022 by the authors. Licensee MDPI, Basel, Switzerland. This article is an open access article distributed under the terms and conditions of the Creative Commons Attribution (CC BY) license (https:// creativecommons.org/licenses/by/ $4.0 /)$.

\begin{abstract}
The article shows the results of measuring the mechanical losses of a piston engine in two new ways and explains the necessary engine modification for these measurements. At the same time, it compares the results of measuring mechanical losses in the internal combustion engine (ICE) in the current (hitherto exploited) way and in new ways. The first method is not replacing the cylinder charge and regulating the cylinder pressure by feeding compressed air through self-acting valves into the cylinders of the motoring engine. The second method is a closed working cycle by means of an exhaust-intake connection, in which the load pressure in the cylinder is adjusted and maintained by a controlled-intake air supply. With the current method of measuring mechanical losses of a reciprocating internal combustion engine (ICE) by motoring, there are less than half the pressures in the cylinder compared to the pressures during real engine operation (i.e., in the combustion mode). Lower pressures in the cylinder reduce the force load on the piston group and the crank mechanism, and the detected mechanical losses in the engine are thus significantly reduced compared to the reality. In the laboratories of the propulsion units of the Faculty of Mechanical Engineering of the Technical University in Liberec, research is underway on a new method of measuring mechanical losses of a reciprocating internal combustion engine by motoring with charge pressure profiles in engine cylinders comparable to cylinder pressures during standard engine operation. The paper shows the results of measuring the mechanical losses of a piston engine in two new ways and explains the necessary adjustment of the engine for these measurements. At the same time, it compares the results of measuring mechanical losses in a reciprocating engine in the current (hitherto used) way and new ways. The first method is not changing the cylinder charge and regulating the pressure in the cylinder by inserting compressed air through automatic valves into the cylinders of the motoring engine. The second method is a closed working circuit involving connecting the exhaust to the intake, in which the charge pressure in the cylinder is set and maintained by a controlled supply of compressed air to the intake manifold. The first method proved to be a more suitable way to investigate mechanical losses in ICE and determine the dependence of these losses on the pressure conditions in the engine cylinder.
\end{abstract}

Keywords: ICE motoring; mechanical loss; thermodynamic analysis; measurement

\section{Introduction}

The measurement of exhaust emissions produced by the internal combustion piston engine is monitored and regulated significantly during road vehicles' driving and approval tests. Particular attention has recently been paid to the amount of $\mathrm{CO}_{2}$ emissions. These depend on the overall efficiency of the ICE, which is determined by the thermal efficiency of the working cycle and the mechanical efficiency of the ICE. Therefore, increasing the thermal efficiency of the ICE and reducing mechanical losses in the engine is still a very topical task in the research and development of piston combustion engines (also due to the considered limits given by the future EURO VII standard). 
A frequently used procedure for determining the effect of various measures on individual subfunctional groups, measuring mechanical losses by motoring the engine at a test bench with a dynamometer or at a special test station, is used to reduce ICE mechanical losses. In both cases, it is necessary to equip the test equipment with a very accurate sensor for measuring torque, stabilizing operating fluid temperatures (coolant, lubricating oil) of the engine and automated recording and possibly also evaluation of monitored quantities. The shortcoming of today's way of measuring mechanical losses in an engine by motoring is the big difference between the pressure in the cylinder when the engine is motoring and the pressure in the cylinder during standard engine operation (i.e., with the combustion of the mixture) [1,2].

Another way to detect ICE mechanical losses is, for example, to calculate the mean effective pressure and mean indicated engine operating pressure from a thermodynamic analysis of the high-pressure engine indication or to extrapolate the fuel consumption pattern from the load characteristics. These methods provide reliable data on total mechanical losses in the engine when measurements are made correctly. However, to find new technical solutions leading to a reduction in mechanical losses in the ICE, such measurements are relatively expensive in terms of time and operation. Since friction losses in the piston group (piston + sealing piston rings) account for the largest share (about 40 to $50 \%$ ) of mechanical losses in the ICE, much attention is paid to the impact of the construction and material performance of the piston group on mechanical losses in the ICE. The research is based on theoretical investigations and model calculations of the friction mechanism of piston rings on the cylinder wall and experiments [3,4].

A simplified view of the main items of lost mechanical energy in ICEs and their share of the total loss of mechanical energy in engines is shown in Tables 1 and 2 [1]. The data on mechanical losses in the ICE are shown in the tables below. They indicate the predominant proportion of friction losses in the piston group and engine bearings. The main potential for finding possible solutions to reduce friction in the ICE is mainly the friction of piston rings. The movement and load of the piston ring in the engine cylinder are very variable during the stroke. The piston rings must minimise the penetration of lubricating oil from the crankcase into the cylinder and the antiblow function of the cylinder charge into the engine crankcases. It is relatively challenging to optimise the piston ring preload, and the shape of the friction surfaces on the piston rings to reduce friction losses. The value of the coefficient of friction can be reduced through coating technologies on the piston rings and improved lubrication technologies.

Table 1. Mechanical loss distribution—share of the indicated power [1].

\begin{tabular}{ccc}
\hline $\begin{array}{c}\text { GROUP (Indicative Values of } \\
\text { Mechanical Losses in \% of } \\
\text { Indicated ICE Power at 100\% Load) }\end{array}$ & $\begin{array}{c}\text { SI Engine } \\
\text { [\%] }\end{array}$ & $\begin{array}{c}\text { CI Engine } \\
\text { [\%] }\end{array}$ \\
\hline $\begin{array}{c}\text { Cylinder cartridge } \\
\text { replacement }\end{array}$ & 3.5 & 3.5 \\
$\begin{array}{c}\text { Water, oil and injection pump } \\
\text { Valve distribution and } \\
\text { actuator accessories }\end{array}$ & 1.0 & 1.5 \\
$\begin{array}{c}\text { Losses in main and } \\
\text { connecting rod bearings }\end{array}$ & 1.5 & 1.5 \\
$\begin{array}{c}\text { Friction of the piston and } \\
\text { piston rings in the cylinder }\end{array}$ & 4.0 & 6.0 \\
Total & 8.0 & 12.5 \\
\hline
\end{tabular}


Table 2. Mutually distributed loss-making mechanical energy [1].

\begin{tabular}{ccc}
\hline $\begin{array}{c}\text { LOSSES (Indicative Values of the } \\
\text { Share of the Main Groups of Losses } \\
\text { in the Total Loss of Mechanical } \\
\text { Energy in ICE at 100\% Load) }\end{array}$ & $\begin{array}{c}\text { SI Engine } \\
{[\%]}\end{array}$ & $\begin{array}{c}\text { CI Engine } \\
\text { [\%] }\end{array}$ \\
\hline $\begin{array}{c}\text { The friction between piston-cylinder } \\
\text { (rings-cylinder) }\end{array}$ & 45 & 50 \\
The friction of crankshaft and \\
$\begin{array}{c}\text { camshaft bearings } \\
\text { Engine cylinder replacement losses } \\
\text { Timing mechanism drive } \\
\text { Drive of auxiliary units }\end{array}$ & 23 & 24 \\
\hline
\end{tabular}

The friction losses on the piston rings are related to the pressure of the piston rings on the cylinder wall, which is determined both by the assembly preload of the piston rings and by the change of the operating pressure in the engine cylinder. The movement and load of the piston ring are very variable during the stroke of the piston in the engine cylinder. The required clearance in accommodating the piston in the cylinder and the piston rings in the piston grooves created a pressure penetration from the cylinder into the piston ring grooves. It was suitable for pressing the piston rings against the cylinder wall. The variability of the load of the piston rings by the pressure in the groove of the individual rings for the supercharged case of the diesel engine is shown in the graphs in Figure 1, which were determined by computational modelling [5].
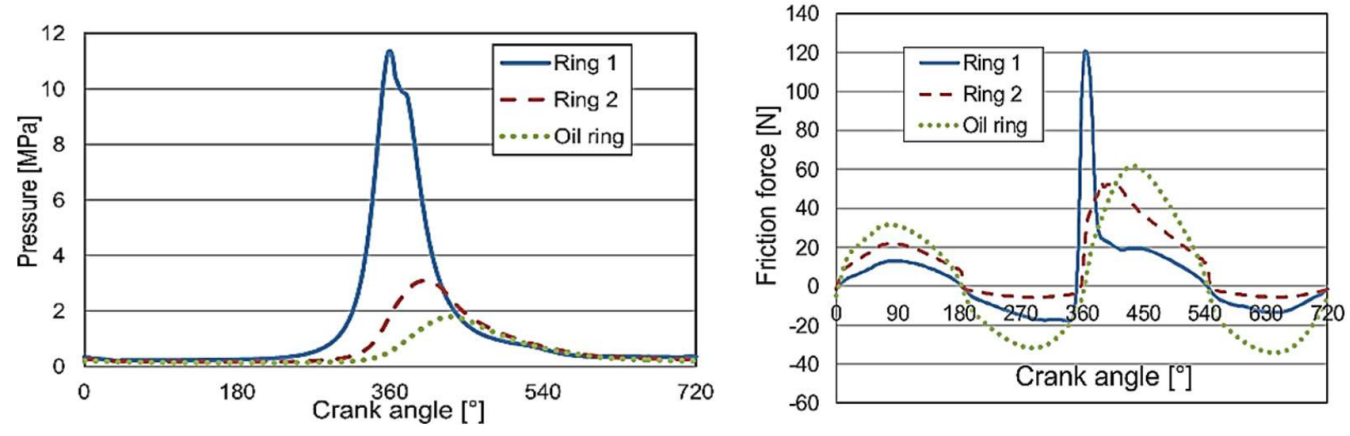

Figure 1. Calculated pressure courses in the grooves of the individual piston rings and their friction forces depending on the position of the crankshaft of the supercharged diesel engine (i.e., the pressure in the engine cylinder) [5].

Measurement of mechanical losses by motoring an ICE with increased pressure in the cylinder (with a closed working cycle using an exhaust-intake connection and a controlled intake of compressed air into the intake manifold) was carried out, for example, AVL [6]. Figure 2a displays a test site with a motoring single-cylinder ICE. A standard steel pipe and hoses connect the intake and exhaust via a large boost pressure vessel. Compressed air is fed directly into the pressured air reservoir. The design of a large pressure reservoir can be explained by the attempt to avoid closed-circuit pressure pulsations (intermittent exhaust-side air inflows and intermittent intake of air on the intake side) when measured by pressure pulsations. Figure $2 \mathrm{~b}$ shows the measured IMEP, $\mathrm{p}_{\max }$ and boost pressure values for the speed in the table. 


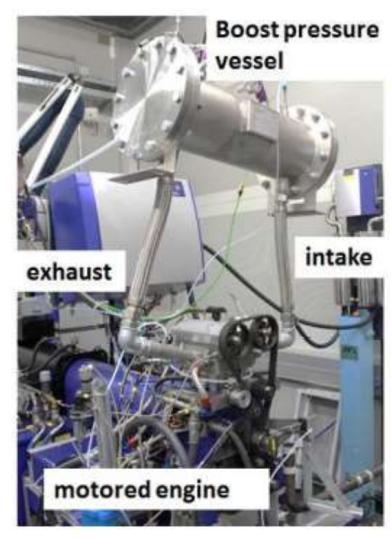

(a)

\begin{tabular}{cccc}
\hline rpm & $\begin{array}{c}\text { IMEP [bar] } \\
\text { equivalent }\end{array}$ & $\mathbf{p}_{\max }[\mathbf{b a r}]$ & $\begin{array}{c}\text { boost pressure } \\
\text { absolute [bar] }\end{array}$ \\
\hline 1000 & 8 & 39 & 2 \\
1200 & 6.5 & 33 & 1.8 \\
1750 & 3 & 21 & 1.05 \\
1750 & 5 & 31 & 1.53 \\
1750 & 8 & 41 & 1.96 \\
1750 & 10 & 51 & 2.4 \\
2500 & 8 & 38 & 1.77 \\
\hline
\end{tabular}

(b)

Figure 2. Test assembly for the boosted-motored friction test (a) with examples of boost pressure levels adjusted to achieve target compression pressure (b) [6].

A diagram of the test site, including a description of the experiment's elements, is shown in Figure 3.

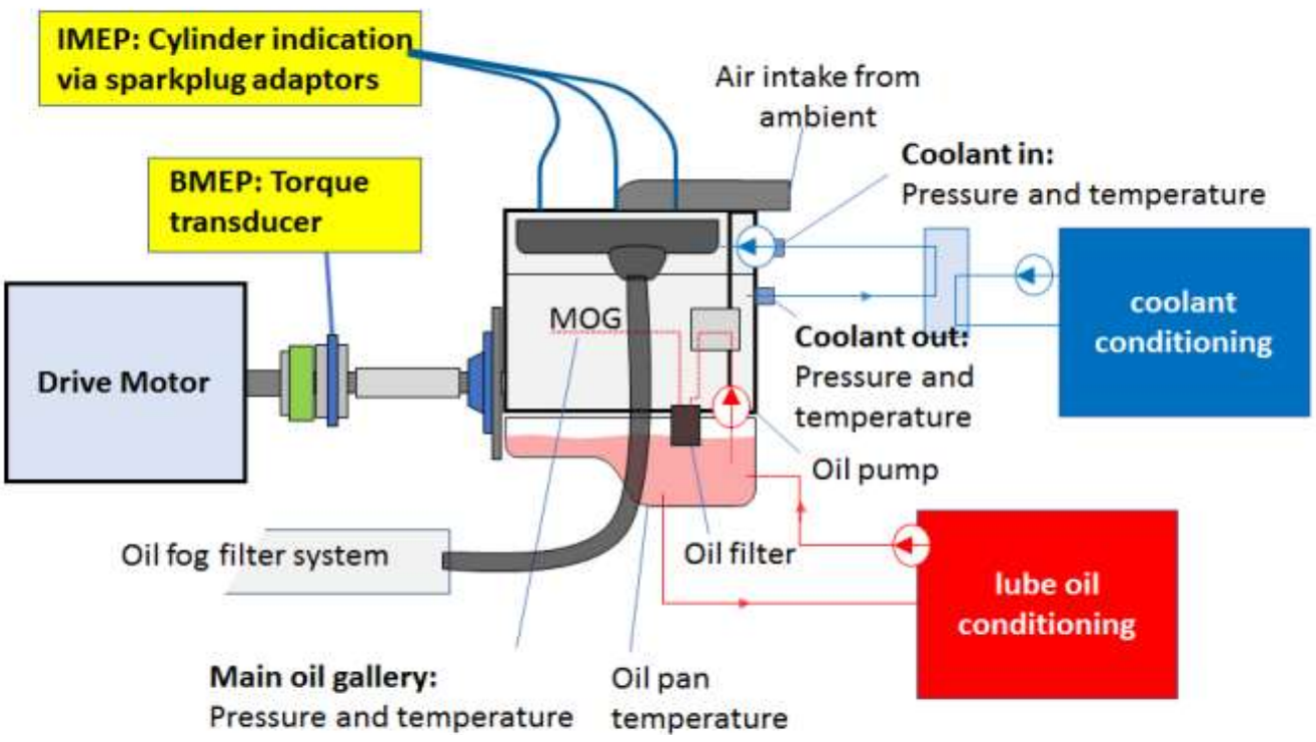

Figure 3. Test assembly for the boosted-motored friction test with examples of boost pressure levels adjusted to achieve target compression pressure [6].

Other similar experiments measuring mechanical losses by motoring ICEs with increased pressure in the cylinder were published in $[7,8]$. This is a similar implementation to [6]. Publications $[7,8]$ are expanded to include detailed simulations using a compression ignition internal combustion engine. Figure 4 shows a test site with a motored diesel engine, where rubber hoses connect the intake and exhaust over a large compressed air supply.

In the literature, the measurement of mechanical losses by motoring an ICE with increased pressure in the cylinder (with a controlled supply of compressed air to the individual cylinders using one-way valves) was not found [9]. 


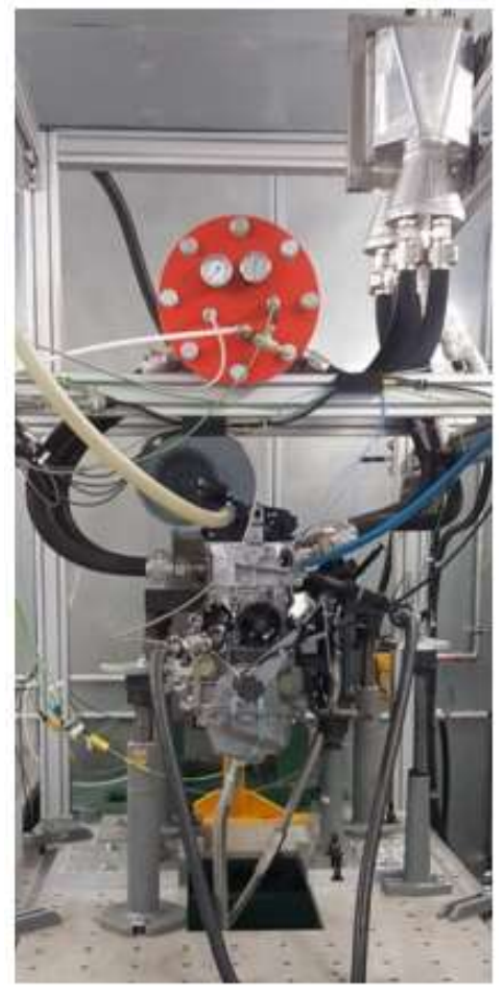

Figure 4. The testbed configuration $[7,8]$.

\section{New Ways to Measure Losses by Motoring an ICE with Increased Pressure}

Experimental research on the following new methods has been carried out on the $1.6 \mathrm{dm}^{3}$ atmospheric spark ignition internal combustion engine MPI series EA211. The basic parameters of the engine used are given in Table 3 below. This positive ignition engine was installed at a special motoring station, equipped with a $26 \mathrm{~kW}$ propulsion three-phase electric motor with speed control by a frequency converter and a system of exchangers to set and stabilise the temperatures of the engine's operating fluids (coolant and lubricating oil). The temperature conditions corresponded to the real operation of the engine. Connecting the motoring engine to the driving electric motor required a flexible clutch assembly and a torque sensor (HBM T40 B, $200 \mathrm{Nm}$ ). While the engine was being motored, the progress of the cylinder pressures was monitored and recorded online using the AVL X-ion indicating apparatus using the AVL 365C optoelectronic incremental speed sensor and the AVL GU21D piezoelectric pressure sensors. Measurement and recording of the engine driving torque, motoring engine operating conditions and cylinder blow-outs (using AVL Blow by meter) to the crankcase were performed using the HBM MGCplus gauge switchboard. All measurements were taken at a hot-engine test station with the coolant temperature stabilised at $85^{\circ} \mathrm{C}$ and lubricating oil temperature at $90^{\circ} \mathrm{C}$. Figure 5 shows the actual state of the test station with the engine installed for motoring.

Table 3. Basic parameters of the engine used.

\begin{tabular}{cc}
\hline Type & SI, 4 Cylinder Inline, Naturally Aspirated \\
\hline Bore $\times$ Stroke & $76.5 \times 86.9 \mathrm{~mm}$ \\
Displacement & $1597.7 \mathrm{~cm}^{3}$ \\
Compression ratio & $10.5: 1$ \\
Maximum power & $80 \mathrm{~kW}$ \\
Maximum torque & $150 \mathrm{Nm}$ \\
Cooling system & water \\
\hline
\end{tabular}



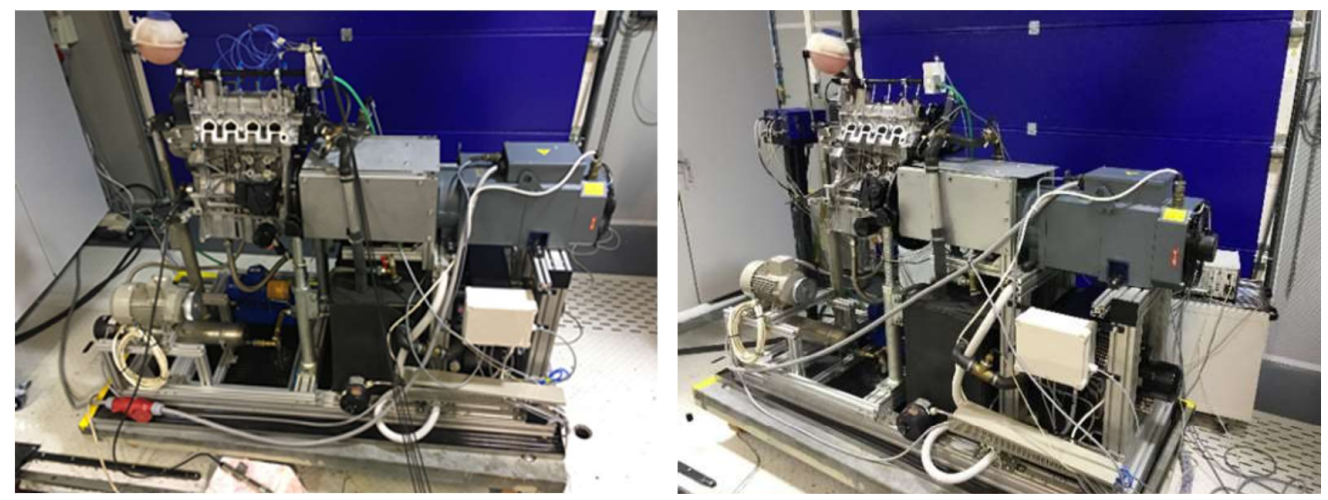

Figure 5. Special habitat for measuring mechanical losses by motoring an ICE with increased cylinder pressure.

\subsection{Option A}

This new way of measuring the mechanical losses of the four-stroke piston engine by motoring requires disconnecting the valve controls on all cylinders so that the valves are permanently closed. Instead of spark plugs, multifunction screws were mounted in the cylinder head, housing self-actuating one-way valves with controlled compressed air supply to individual cylinders, pressure transducers and decompression screws. The schematic image and photograph in Figure 6 show the arrangement of a cylindrical engine unit with a multifunction screw and a cylinder head section with pressurised air connections to single-way valves. Photographs of a manufactured functional multifunction screw sample with individual component markings, including the 3D model, are shown in Figure 7.
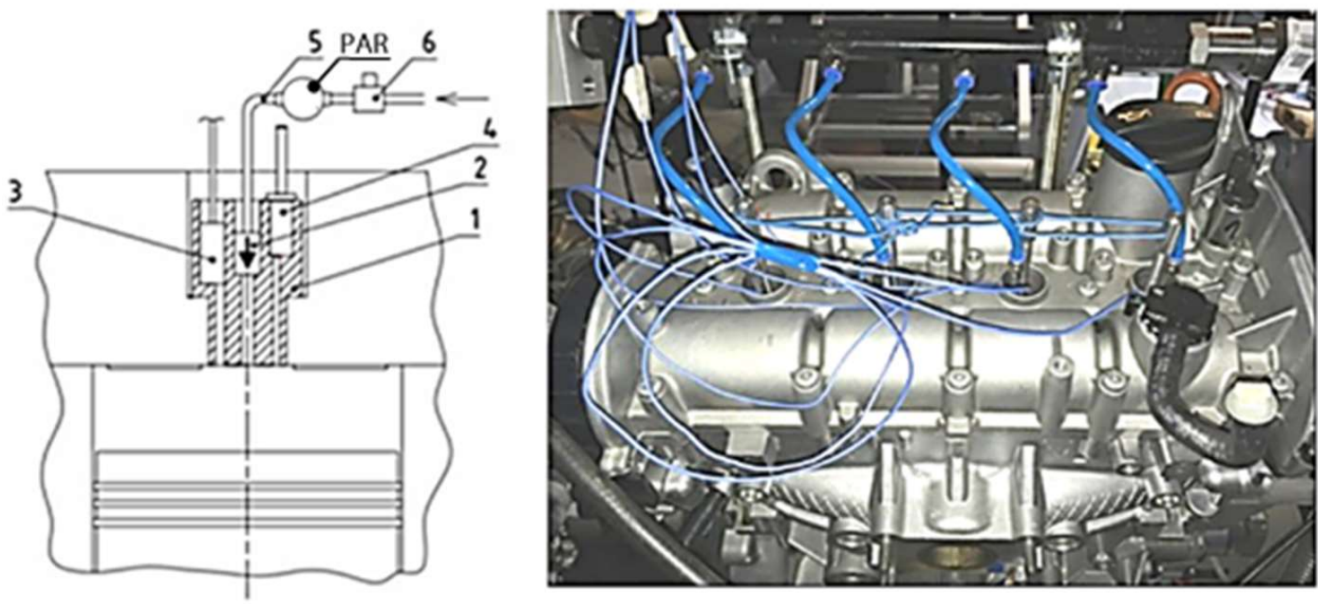

Figure 6. Arrangement of a cylindrical engine unit with multifunction screw and a cylinder head section with compressive air connections to single-way valves. Describing part of the left picture: multifunction screw diagram (1) with a special self-actuating one-way valve (2), a pressure transducer (3) and decompression screw (4). View of the top portion of the cylinder head with installed multiblower screws with the connection of one-way valves by inlet (5) to the pressurised air reservoir (PAR = "pressured air reservoir") with regulator (6) to adjust the air pressure in PAR. 


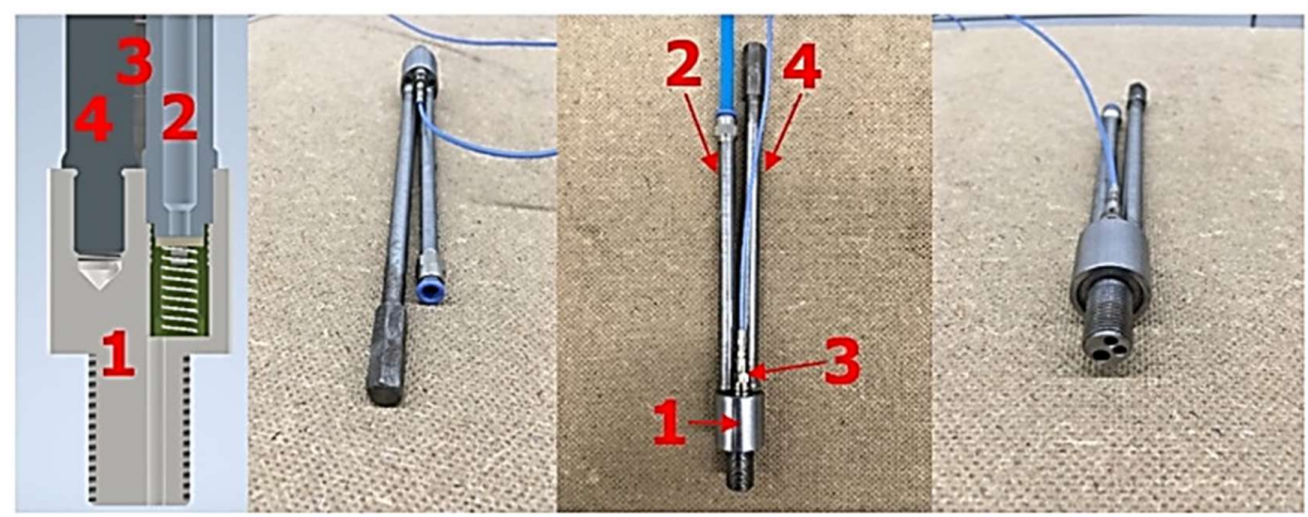

Figure 7. Option A: multifunction screw diagram (1) with a special self-actuating one-way valve (2), a pressure transducer (3) and decompression screw (4).

A detailed view of the 3D model of the multifunction screw (1) with individual component markings is shown in Figure 8. A screw (4) was screwed into the multifunction screw on the left. Decompression reduces the highest value of the driving torque of the motored engine both when starting and when increasing the speed and when stopping the motoring. This solution ensures a reduction in torsional vibrations in the rev area of approximately $500-1000 \mathrm{~min}^{-1}$, which contains a separate torsion set frequency at the motoring station (motoring engine, flex clutch, torque sensor and electric drive motor). On the right, a compressed air supply batch is shown through the self-actuating one-way valve (2) to the engine cylinder. The one-way self-actuating valve shall be guaranteed cylinder tightness and guaranteed flow from the compressed air supply to the cylinder. The design is as follows: flat end of the compressed air supply pipe (2) (has a hardened, ground and polished surface), to which a steel (hardened, ground and polished) plate (7) was pressed with a slight spring preload, which was put together with the spring (8) housed in a housing (9) mounted on the end of the pipe. The arrangement and dimensions of the end part of the tube, sleeve and plate determined the stroke of the plate in the range of $0.2-0.3 \mathrm{~mm}$.

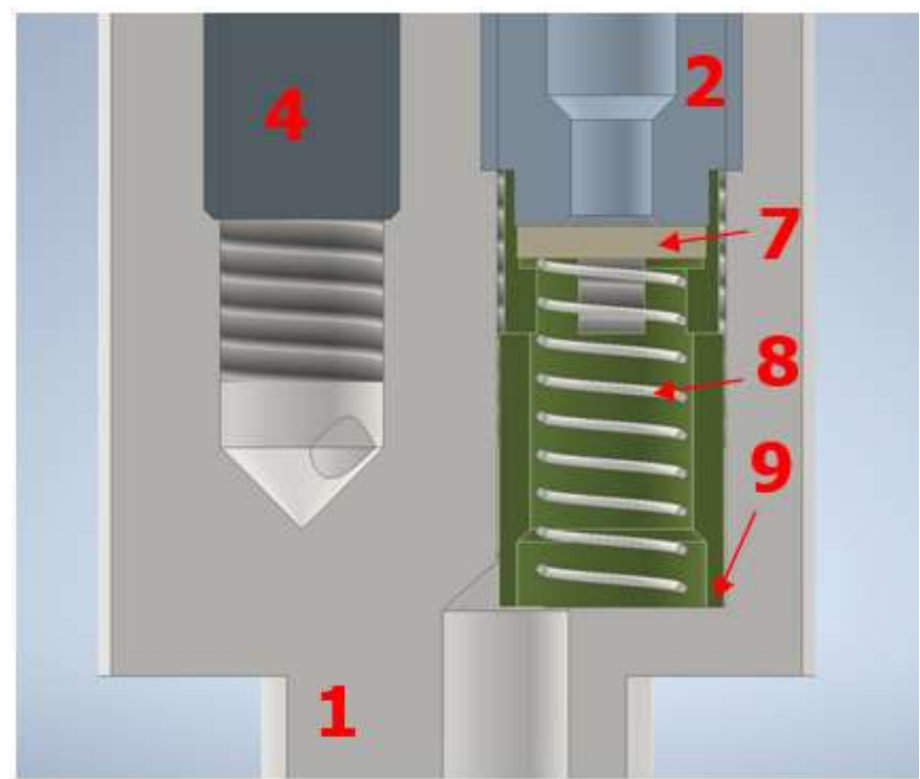

Figure 8. Detailed view of 3D model of the multifunction screw (1) with individual component designations: self-actuating one-way valve (2), decompression screw (4), plate (7), spring (8) and casing (9). 
When motoring a four-stroke engine with permanently closed valves in the cylinder, the cylinder contents are removed from the operating cycle, and both the compression and expansion phases occur at twice the frequency. The pressure sets the required maximum pressure in the cylinder in the compressed air supply to the one-way automatic valve in the multifunction screw. The self-adjusting valve continuously replenishes the filling in the cylinder when measured (compensating for the loss of filling by the prop and the drop in pressure due to heat loss). It automatically keeps the set pressure in the cylinder to the required value-shown in Figure 9.

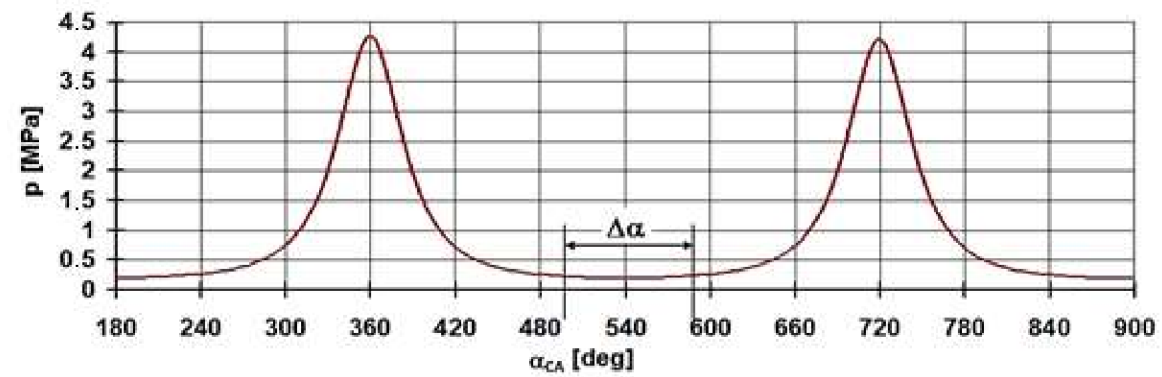

Figure 9. Calculated pressure flow in the engine cylinder with valves closed with an initial pressure of $200 \mathrm{kPa}$. Replenishment of the air charge of the cylinder with an automatic valve takes place when the crankshaft is around the top dead centre TDC $\left(\Delta \alpha=30 \sim 40{ }^{\circ} \mathrm{CA}\right)[10] . \alpha=\varphi$.

A schematic arrangement of Option A of the test bench is shown in Figure 10. The asynchronous electric motor was connected to the ICE with flexible coupling, where the rotor of the torque sensor was screwed on one side of the flange. When motoring the ICE, the cylinder charge (compressed air) was fed through the air valve (allowed the compressed air pressure to be set) and the "pressured air reservoir" = PAR. From PAR, the compressed air was distributed by the individual pressure hoses through the self-actuating one-way valves into the individual cylinders of the engine. The test bench was equipped with a system for stabilising the lubricating oil and engine coolant temperatures (heating and cooling system including external pumps). The necessary temperature and pressure sensors were located on the ICE to ensure that the engine ran smoothly. The experiment's data recording was collected through two independent devices-the AVL X-ion indication apparatus (measurement of high-pressure indication in the engine cylinders) and the MGCplus measuring control panel (measurement of temperatures, pressures, torque and blow-by). The entire station was controlled via a PC by a test operator.

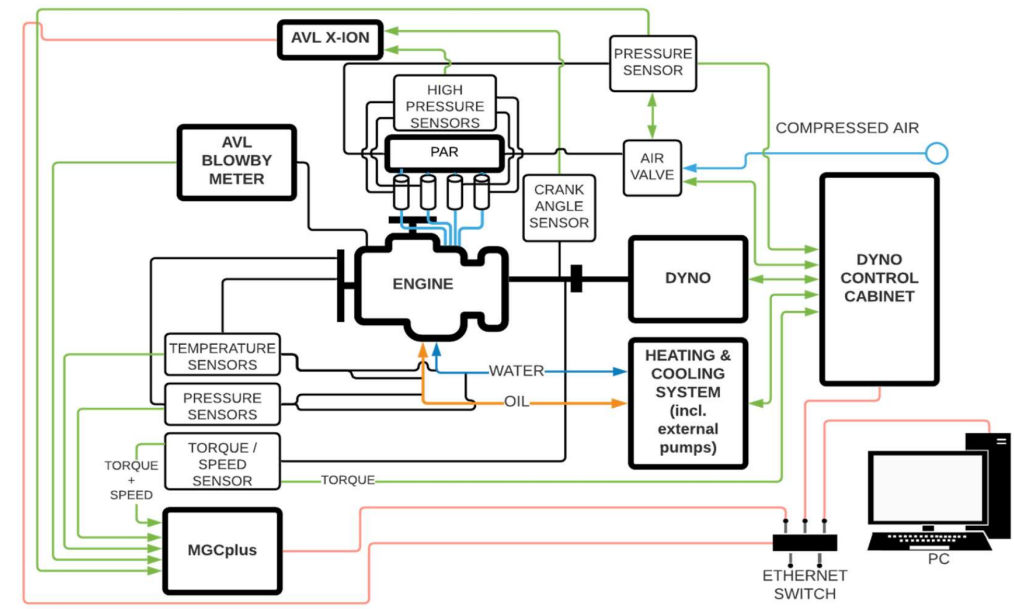

Figure 10. Engagement scheme-Option A. 


\subsection{Option $B$}

A closed working circuit can also realise the increase in pressure in the cylinders of a motoring engine by connecting the exhaust with the intake, in which the controlled supply of compressed air to the intake manifold sets and maintains the cylinder pressure at a value corresponding to the beginning of the compression stroke. It is motoring a classic four-stroke engine (with fully functional valves). Implemented modifications on the internal combustion piston engine, including a separate equal pressure pipe connecting the intake to the exhaust, are shown in the photographs in Figure 11.
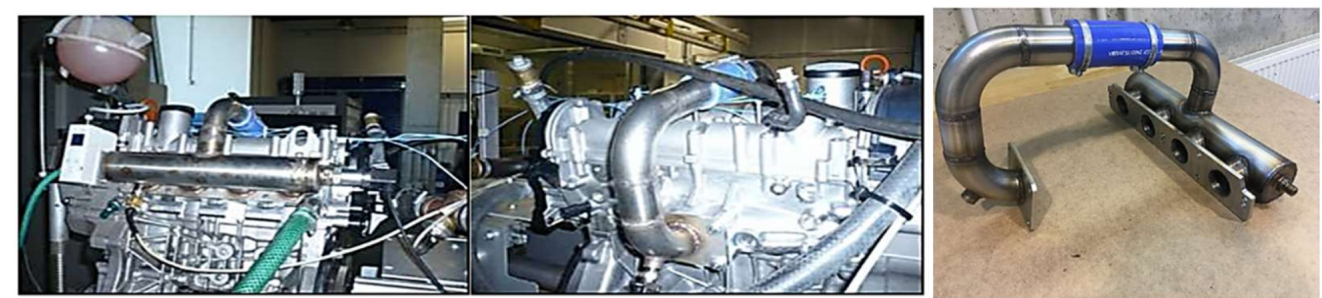

Figure 11. Option B: Construction of a straight pressure pipe connecting the intake to the exhaust mounted on the internal combustion piston engine.

A schematic arrangement of Option B of the test bench is shown in Figure 12. A description of the test bench and its individual parts is given in the description of Figure 10. The main difference is found in the installation on the engine. With Option B, the cylinder charge (compressed air) was also fed via the air valve (allowed the compressed air pressure to be set) to the "pressured air reservoir". PAR is the part that connects the intake to the exhaust.

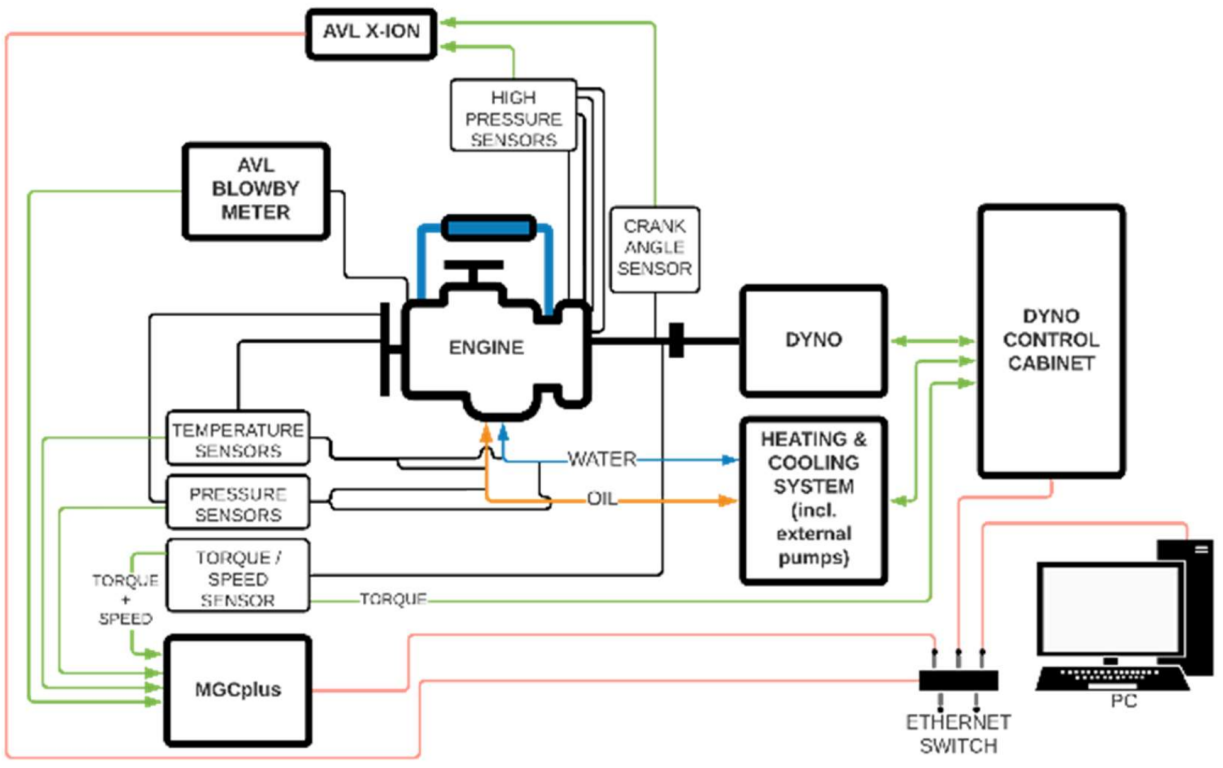

Figure 12. Engagement scheme-Option B.

\section{Results of Measuring Mechanical Losses by Motoring ICE with Increased Pressure in the Cylinder in New Ways}

\subsection{Option A-Measurement Results}

The measurements demonstrated that the self-operating valves, depending on the air pressure of the container (PAR) to which the air ducting tubes to the compressed air supply pipe to the valve are connected, have a reliable function over the entire speed range of the motored engine (2000-5000 $\left.\mathrm{min}^{-1}\right)$. Minor differences in the pmax values of the individual engine cylinders were due to variations in the flow and dynamic characteristics of the individual valves in the multifunction screws, which decide the pressure settings 
at the start of the compression strokes in the individual cylinders. A record of the actual progress of cylinder pressures in the $4000 \mathrm{~min}^{-1}$ mode and PPAR $=5$ bar is shown Figure 13 .
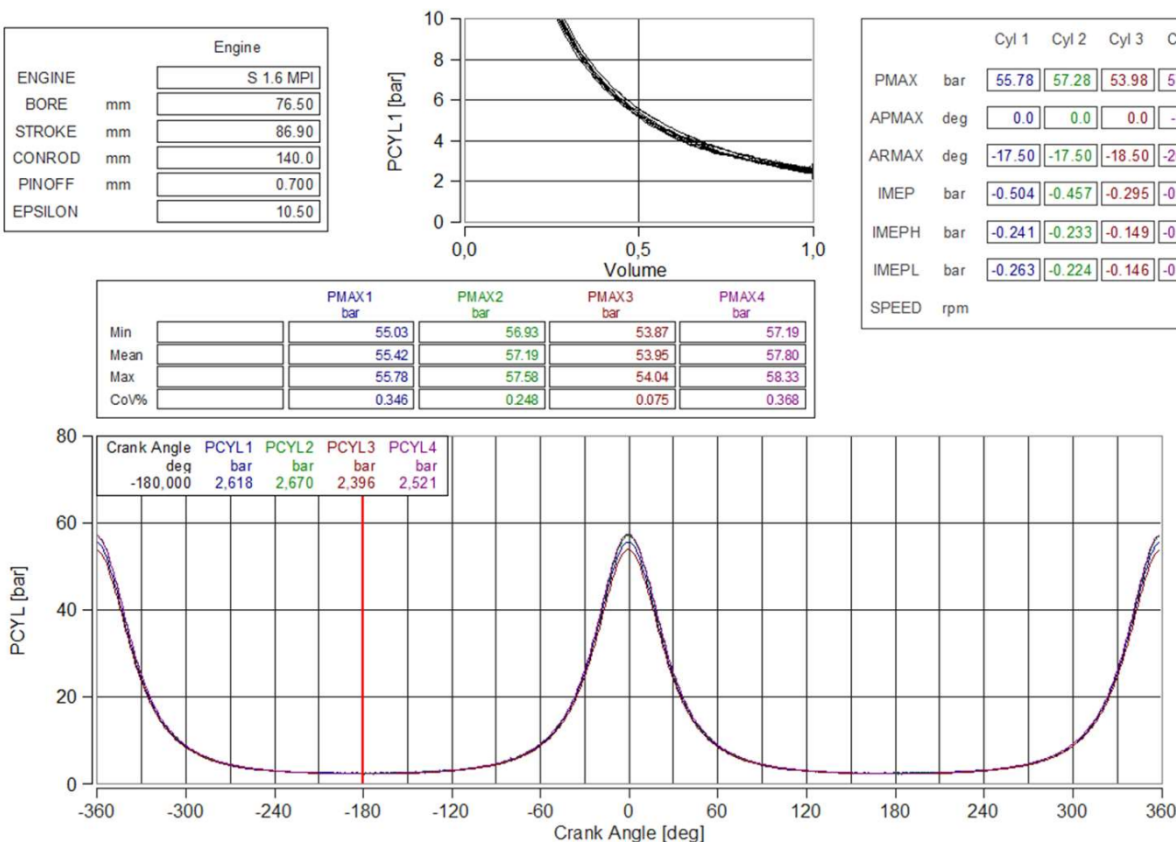

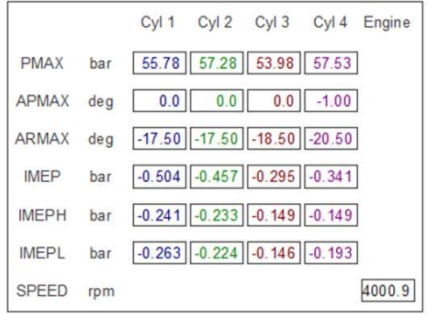

4000.9

Figure 13. Record of the actual progress of the pressures in the individual cylinders from the engine motoring in the $4000 \mathrm{~min}^{-1}$ modes at the pressured air reservoir air pressure (PAR) PPAR $=5$ bar.

Inserted tables show both the current $\mathrm{P}_{\mathrm{TDC}}$ values and their statistical evaluation in a set of 200 consecutive cycles; in a small table at the top left, the current PBDC $_{\text {Balues in }}$ each cylinder are shown, and a larger table at the top right shows the IMEP values from the thermodynamic analysis of the current cycle. The table at the top left of the graph shows the current pressure value in each cylinder at the start of the compression stroke.

The measured mean torque values of the $\mathrm{T}_{\mathrm{q} \_ \text {loss }}$ motored engine are the combined result of mechanical losses in the ICE and thermodynamic losses in the motored engine operating cycles. The mechanical work to change the volume of the cylinders is zero for an engine with permanently closed valves. Thermodynamic losses in working cycles (heat transfer between the cylinder volume and the walls and losses by leakage of the air charge mass) were determined by thermodynamic analysis of the measured pressure profiles in the individual cylinders. For thermodynamic analysis of a motored engine with permanently closed valves, the mean indicated pressure of the thermodynamic workflow loss (i.e., for two crankshaft revolutions) is

$$
\text { IMEP_td-loss }=\text { IMEPH }- \text { IMEPL }
$$

The IMEPH (Indicated Mean Effective High Pressure) and IMEPL (Indicated Mean Effective Low Pressure) values for a multicylinder engine are determined as the average of the thermodynamic analysis results of the measured pressure courses in all cylinders. The total mean indicated loss pressure IMEP-loss(sum) for the motored engine is calculated from the measured torque of the motored engine $\mathrm{T}_{\mathrm{q} \_ \text {loss }}$. The entry for the mean indicated pressure of mechanical losses in the working cycle (i.e., for two crankshaft revolutions) in the motored engine is determined by subtracting IMEP_td-loss from IMEP_loss(sum).

The results of measuring the mechanical losses in the piston engine by the new motoring method were compared with the results of measuring the mechanical losses in the standard way on the same ICE [11] for which the measurements were made at the same motoring station under the same conditions. The motoring engine was free of suction and exhaust piping. The results of the comparison are shown in Figures 14 and 15. 
Comparison of 2 variants - var. A and standard

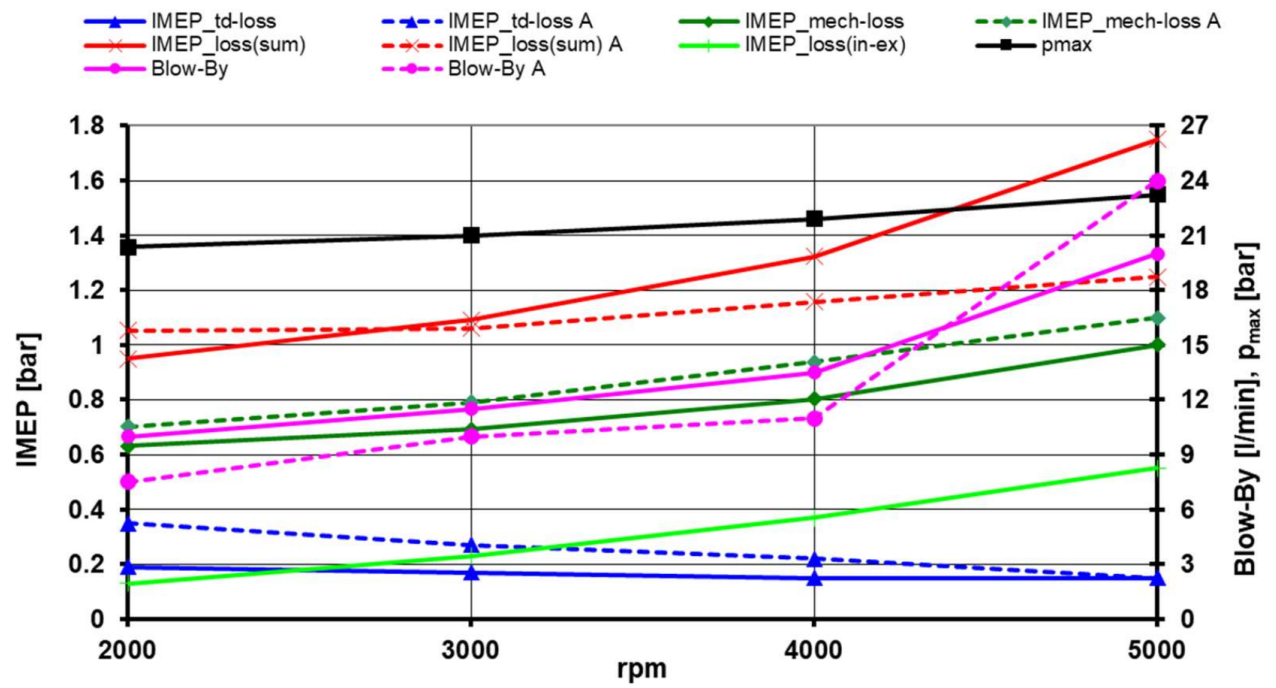

Figure 14. Record the actual progress of the pressures in the individual cylinders from the engine motoring in the $4000 \mathrm{~min}^{-1}$ modes at the pressured air reservoir air pressure (PAR) PPAR $=5$ bar.

For both the standard and new modes, Option A, the observed quantities were determined by measurements for the same mean $p_{\max }$ values in the engine's cylinders in the individual rev modes of the engine. When measuring losses in the piston engine by the standard motoring method, the mean indicated loss pressure IMEP-loss(sum) was more significant than when motoring the engine with the valves permanently closed. This is due to the mean indicated loss pressure item for replacing the IMEP ${ }_{\text {loss(in-ex) }}$ cylinder content for the standard motoring method (this item is not available for permanently closed valves). The mean indicated mechanical loss pressure IMEP_mech-loss was higher when the engine was motored with the valves permanently closed than when the engine was motored in the usual manner. The graph in Figure 15 shows the subparts of the mean mechanical loss item IMEP_mech-loss when motoring the engine in the standard way for compression and expansion (C-E) and exhaust and intake (Ex-In). The complete characteristics for Option A are shown in Figure 16.

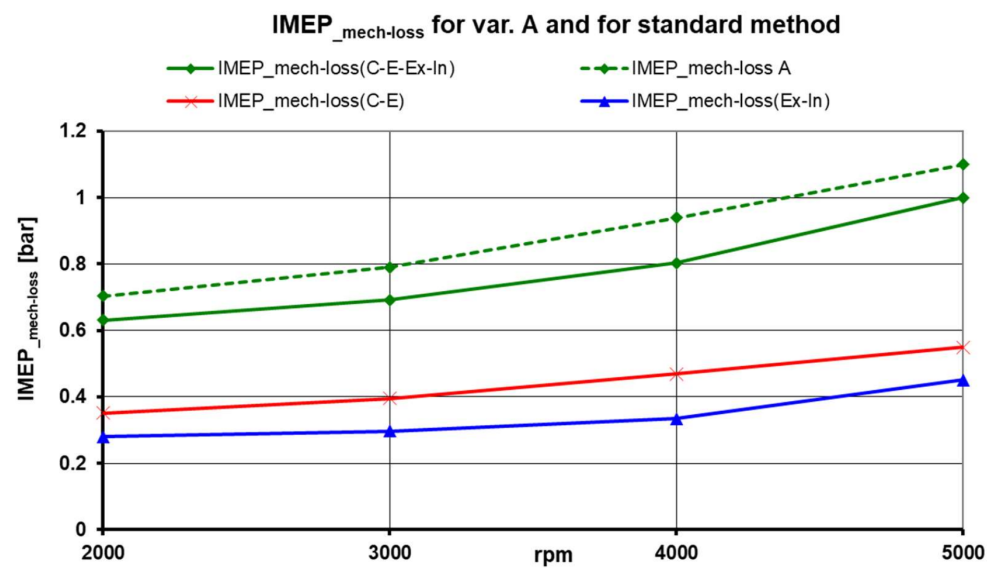

Figure 15. The mean indicated mechanical loss pressure IMEP_mech-loss when the engine was motored in the usual manner can be expressed as the sum of the IMEP_mech-loss mean indicated pressure item for compression and expansion IMEP_mech-loss(C-E) and the IMEP_mech-loss(Ex-In) mean indicated mechanical loss pressure item for exhaust and suction. 


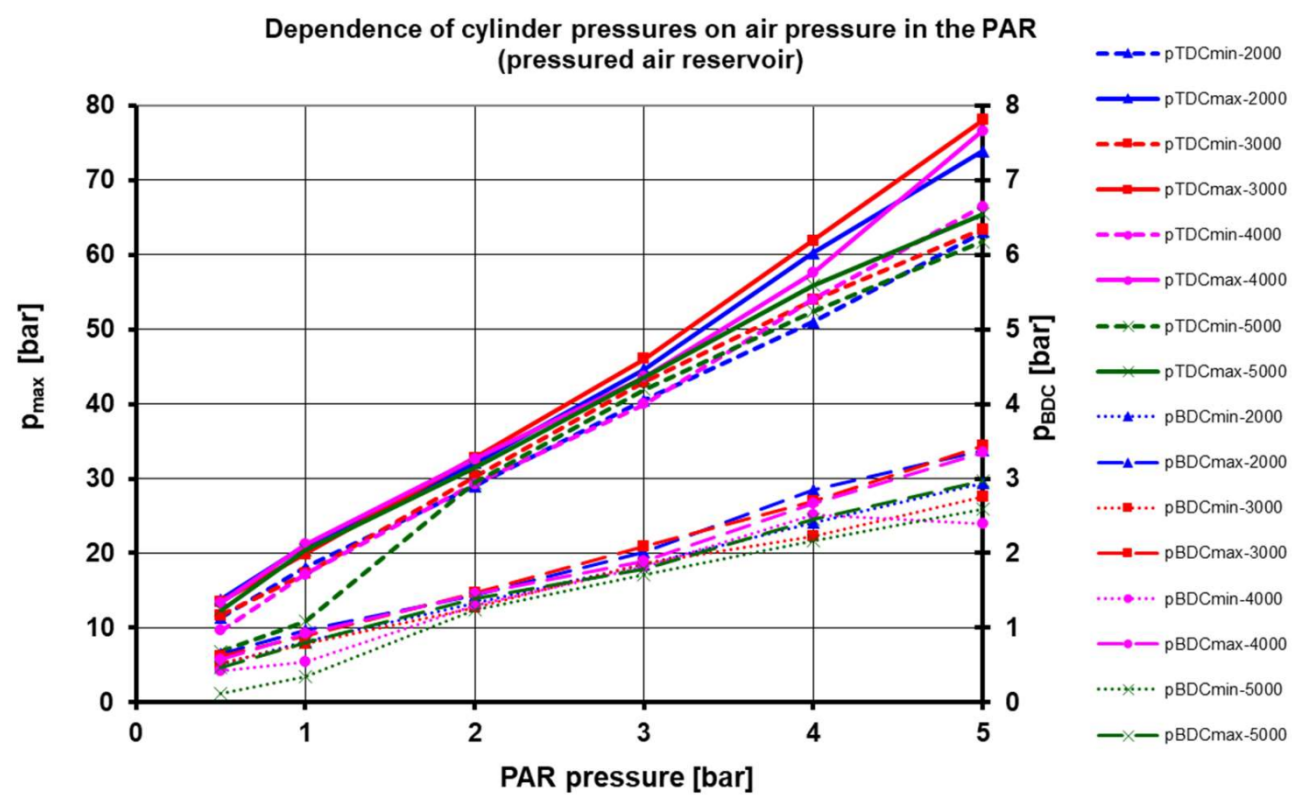

Figure 16. Values of the pressures in the engine cylinders at the start of compression $\left(\mathrm{p}_{\mathrm{BDC}}\right)$ and the end of compression ( $\mathrm{p}_{\mathrm{TDC}}$ ), subtracted from the records of the high-pressure indication in the wide operating area of the motored engine. The variation of the observed maximum pressures in the engine cylinders was roughly equal to the variability of the maximum pressures in the cylinder of the positive ignition engine.

If the maximum cylinder pressures are the same when motoring the engine in the usual manner and motoring with the valves closed (Option A), then the IMEP_mech-loss(C-E) item will have half the IMEP_mech-loss measured when motoring the engine with the valves closed. The piston was loaded with pressure during compression and expansion at each crankshaft revolution when motoring the engine with the valves permanently closed. Therefore, the IMEP (indicated mean effective pressure) of mechanical losses was higher than when motoring the engine in the standard way.

\subsection{Option B-Measurement Results}

The measurement results for Option B with a closed working circuit using the connection of the exhaust with the intake and the controlled supply of compressed air to the intake manifold showed that the IMEP values of the working circuit of the motoring engine are in good agreement. In the experiment, however, there were pulsations in the relatively small volume of closed circulation caused by the tailpipe's intermittent air inflows and intermittent intake-side air samples. These pulsations affected the reliability of the measurement of the cylinder capacity exchange work (IMEPL) and thus the reliability of the determination of the mechanical losses in the cranking engine. The pressure variation is also evident in the recording of the pressure in the cylinder in Figure 17.

Online thermodynamic analysis and statistical processing were performed in the same way as during engine motoring with permanently closed valves for Option A. Work on the replacement of cylinder contents (see pressure patterns in the low-pressure area in Figure 13) showed a gradual increase in temperature at the start of the compression stroke, which complicated the course and execution of the measurement. Due to the abovementioned issues in this experiment for Option B, only Option A will be further detailed. 


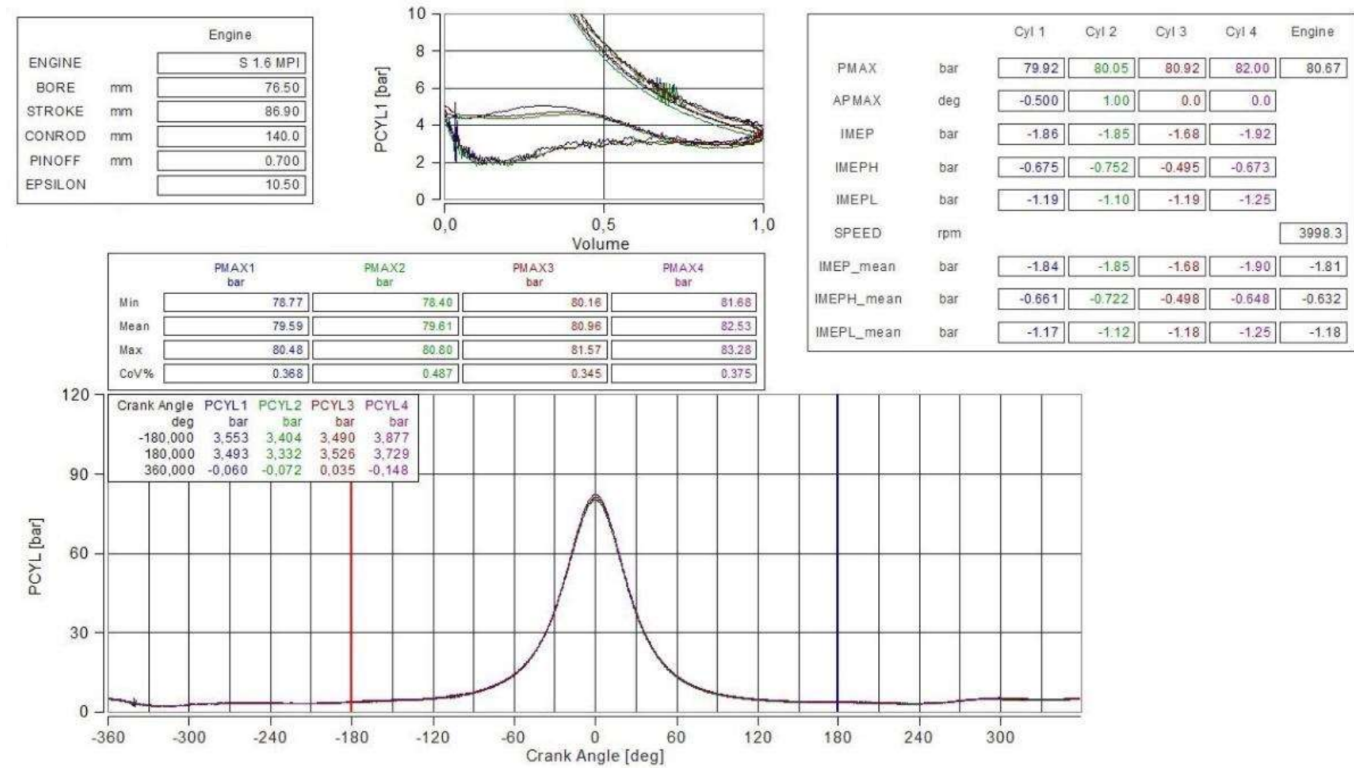

Figure 17. Record of the actual progress of the pressures in the individual cylinders from the engine motoring in the $4000 \mathrm{~min}^{-1}$ modes at air pressure in the intake manifold pPAR $=3.5 \mathrm{bar}$.

\section{The Working Cycle of Motoring Engine with Permanently Closed Valves-Option A}

The measurements showed the dependencies of both friction and thermodynamic losses of the engine at both speeds and maximum pressures in the cylinder of the motoring engine. Analysis of the high-pressure indication in all cylinders of the cranked engine confirmed that blowing compressed air into the cylinders by self-actuating valves provides a rapid build-up of pressure in the cylinders, which can be easily controlled by air pressure flow to the valves. The measurement also showed that the new air charge state in the cylinders would stabilise after several hundred work cycles (i.e., after 3-6 s) from the air pressure setting on the inflow to the valves. As the pressure was the only measured quantity of the filling in the cylinder, a calculation study was conducted to investigate the state of the filling in the cylinder. The purpose of the calculations was to create a theoretical view of the method of increasing maximum pressures in cylinders of a motoring engine with permanently closed valves and the rate of stabilisation of the operating circuit parameters from the moment of setting the air pressure in the reservoir with the injection of compressed air through the self-actuating valve into the cylinder, as well as the state of the working load in the cylinder (mass, pressure and temperature in BDC) compared to the measurements of $\mathrm{p}_{\mathrm{BDC}}, \mathrm{p}_{\max }$ and blow-by. The correctness of the calculated result can only be partially verified by comparing the calculated pressure of $\mathrm{P}_{\mathrm{BDC}}$ and $\mathrm{p}_{\mathrm{TDC}}$ in the cylinder after the calculated steady-state had been reached with the corresponding values of the pressures in the cylinder, as determined from the evaluation of the high-pressure indication. The other calculated values of the cylinder contents, mass $\mathrm{m}$ and $\mathrm{T}_{\mathrm{BDC}}$ temperature, after reaching the steady-state in the cylinder, need to be considered (concerning the estimation of some input data for calculations) only probable (their mutual binding is determined by the equation of state-e.g., for BDC). As the calculations included the modelling of the motoring engine's operating cycle with permanently closed valves, the calculated value of thermodynamic losses from the "calculated" steady-state circulation can be compared to the IMEP_td-loss from a thermodynamic analysis of the high-pressure indication of measurements taken, and this comparison can also be considered as a criterion for the accuracy of the results of the calculation study.

The thermodynamics of the working cycle and the $\mathrm{p}_{\max }$ control mechanism in a cylinder of a motoring engine with permanently closed valves by applying compressed air to the working cycle to set the required $\mathrm{p}_{\max }$ pressures in the steady-state mode of the motoring engine is a seemingly simple problem. Still, it took some time to find the right 
approach to describe the events in the engine cylinder. Due to the relatively very rapid stabilisation of the working cycle monitors as well as the measured torque (loss) of the cranked engine, the study of the progress of changes in the cylinder was aimed at achieving a steady operating state from the setting of a specific (selected) PPAR air pressure value in the reservoir.

To clarify the situation at the start of the engine's revving with permanently closed valves, a visualisation is given in Figure 18, which shows a record of the progress of the pressures in each cylinder in the $5000 \mathrm{~min}^{-1}$ modes and the overpressure in the pressurised air reservoir, i.e., $\mathrm{P}_{\mathrm{PAR}}=6.5$ bar. When motoring the engine at the motoring station, decompression screws were allowed on all cylinders to make the engine run, and when the engine started, the screws were gradually tightened. There was zero pressure in the pressure reservoir. The cylinders had very different pressure courses, determined by the cylinder load state when the decompression screws were touched. The supply of pressurised air to the container ensured rapid equalisation of the pressures in the cylinders so that when the PPAR pressure was set, working pressures increased in all cylinders.

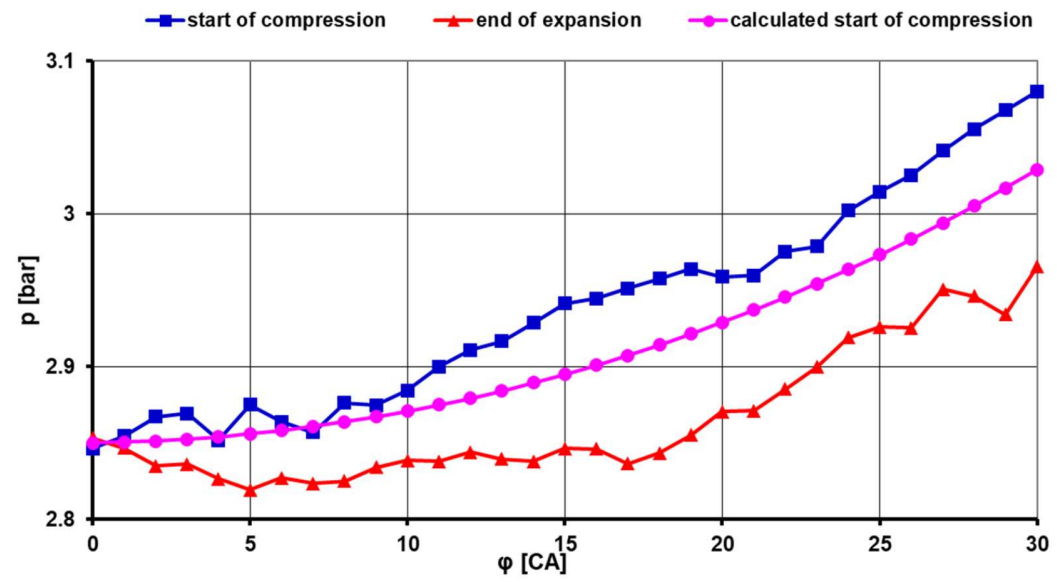

Figure 18. Pressure courses from the indication recording in cylinder one at the start of compression (blue) and end of the expansion (red) in mode $\mathrm{n}=5000 \mathrm{~min}^{-1}$ and air pressure in the inlet to the automatic valve $\mathrm{P}_{\mathrm{PAR}}=6.5 \mathrm{bar}$. The pink line is the polytropic flow of pressure from the calculation.

The air supply from the self-adjusting valve to the cylinder at the end of expansion and the beginning of compression prevented a simple conversion between measured pressures $\mathrm{P}_{\mathrm{BDC} \text { (measured) }}$ and $\mathrm{P}_{\mathrm{TDC} \text { (measured) }}$ over the compression ratio. Pressure courses in the cylinder in the area around the BDC are shown in Figure 19. In the steady mode of a motoring engine with permanently closed valves, in a set of 200 consecutive operating cycles of the same cylinder, the pressures in the BDC deviated at the end of expansion and start of compression to about 0.05 bar.

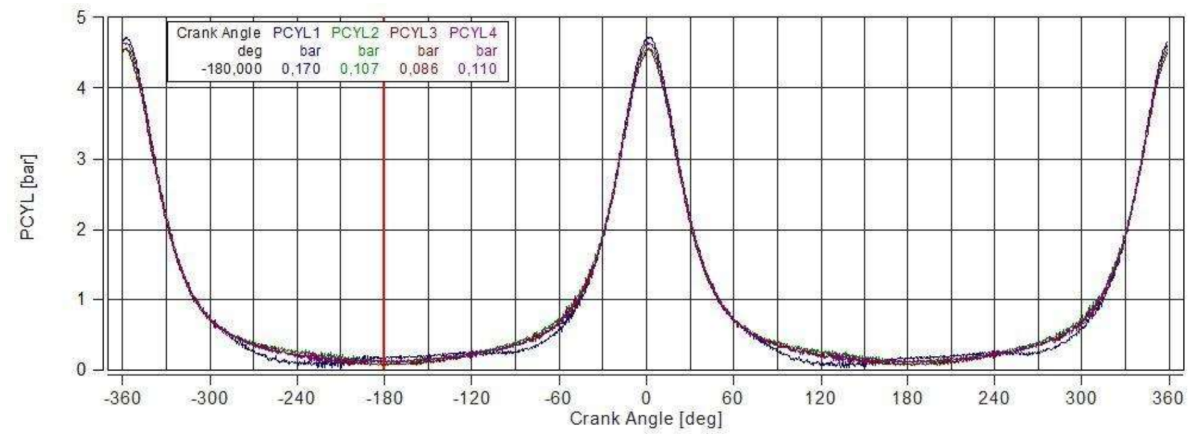

Figure 19. Pressure courses in each cylinder at $5000 \mathrm{~min}^{-1}$ and $\mathrm{pPAR}=0$ bar after starting the motoring (after gradually closing the decompression screws). 


\section{Calculating Cylinder Load State-Option A}

This section investigates the characteristics of a closed operating cycle for an engine with permanently closed valves and a controlled air supply to the cylinder while increasing $p_{\max }$ when cranking the engine from the setting of the PPAR air pressure in the air reservoir to the final settling of the operating cycle parameters. It was based on a combination of calculating successively infused doses of compressed air through a self-actuating valve into a cylinder and modelling the workflow in a computing program.

The arrangement of the compressed air supply system to the self-actuating valve with individual component markings is shown in Figure 20. The compressed air temperature on the inlet to the self-closing valve was approximately $350 \mathrm{~K}$. The calculation of compressed air doses into an engine cylinder with permanently closed valves was based on the solution of compressed airflow through the system from the compressed air storage chamber through the volumes V1 (pressure hose) and V2 (tube terminated by a self-closing plate valve) to the output cross-section S3 (with full-plate stroke) and the ducts to connect with the engine cylinder. The cross-sections S1 and S2 were formed by interconnecting elements between the air reservoir and the volumes V1 and V2. To simplify the calculation, these volumes were combined into a volume $\mathrm{V} 3=\mathrm{V} 1+\mathrm{V} 2$, which was connected to the reservoir by a replacement $S_{\text {RED_cross-section. The flow characteristics of the individual cross-sections }}$ are expressed by their cross-sections and flow coefficients.

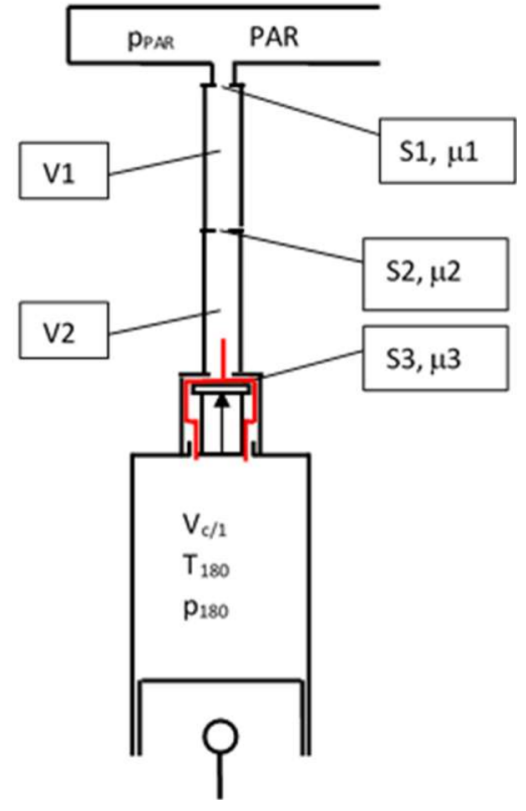

Figure 20. Arrangement of the compressed air supply system to a self-actuating valve with individual component markings.

The calculation solution of the self-actuating valve to the engine cylinder and the modelling of the closed operating cycle in a cylinder-motored engine with permanently closed valves for successive cycles was built on certain simplifications based on the actual calculation program's measurement conditions as developed by the TU Liberec.

The transfer of heat between the filling and the walls of the cylinder was addressed in the computational program according to the Woschni empirical relationship. The mean wall temperature in the cylinder of the motored engine with permanently closed valves was raised against the temperature of the heated engine, taking into account the temperature load on the walls of the cylinder and on the face of the piston from the friction of the piston rings in the closed working cycle, which can only be cooled by transferring heat to the cylinder filling. For the modelling of polytropic compression and expansion in the computing program, the mean wall temperature in the cylinder was set from $390 \mathrm{~K}$ (motoring 30 cycles after setting the pPAR pressure when $p_{\max }$ was low in the cylinder) to 
$420 \mathrm{~K}$ for the $5000 \mathrm{~min}^{-1}$ modes under investigation, after several test calculations, when the $p_{\max }$ pressure in the cylinder was increased until the cylinder load state stabilised.

The calculation was performed cycles after the selected air reservoir pressure setting. For the initial cycle, the $\mathrm{M}_{\text {air }}$ cylinder's $\mathrm{p}_{180}$ pressure and air charge weights were chosen, and the $\mathrm{T}_{180}$ temperature was calculated. Calculations have shown that the choice of $\mathrm{p}_{180}$ pressure and $\mathrm{M}_{\text {air }}$ mass for the initial cycle will have virtually no effect on the final result of the calculation, manifesting only in the number of cycles until a steady state in the cylinder is reached.

The entire calculation procedure includes the following steps:

1. The flow of the individual cross-sections in the system from the pressurised air reservoir to the cylinder was calculated as a subcritical polytropic discharge of the compressible fluid through the $\mathrm{S} 3$ cross-section. The possible critical discharge in the initial phase of the compressed airflow through the S3 section into the cylinder was neglected. In the V3 volume, at the beginning of the discharge, there is always a PPAR pressure which decreases significantly when opening the automatic valve plate as the inflow of compressed air through the $\mathrm{S}_{\mathrm{RED}}$ cross-section into the V3 volume is lower than the discharge through the S3 cross-section. In addition, the complexity of the flow path (see red line in Figure 21) from the valve to the cylinder virtually eliminates critical discharge. The pressure drop for the discharge through the S3 cross-section was determined in each addressed cycle by the difference of the mean pressure in the V3 volume at the discharge of the compressed air through the S3 cross-section (a simplistically constant mean pressure during the discharge, close to the $\mathrm{p}_{\mathrm{BDC}} \mathrm{measured}$ value) and the instantaneous pressure in the $\mathrm{p}_{180}$ cylinder, as calculated;

2. The temperature of the compressed air introduced into the cylinder by the selfadjusting valve was estimated to be $T_{\text {air blow in }}=350 \mathrm{~K}$ (polytropic discharge through cross-section S3 with internal losses and heating of the flowing air through the valve walls and through the cylinder air inlet ducts, which are in the hottest part of the cylinder head);

3. Compressed air is infused into the cylinder in the area $\Delta \varphi$ around the BDC. The values of $\Delta \varphi$ were, according to $p-\varphi$ diagrams on Figure 21 , significantly higher than initially anticipated. In virtually all modes, they point to a vector area of approximately $200{ }^{\circ} \mathrm{CA}$ around the BDC, therefore, taking into account some plate motion dynamics in the self-closing valve; the range $\Delta \varphi=150{ }^{\circ} \mathrm{CA}$ was set for the calculations;

4. Projects also influenced the state of the filling in the cylinder during the motoring: the props were simplified in each cycle by recalculating the measured props in a given motoring mode in the pressure ratio of $\mathrm{BDC} \mathrm{p}_{180 \text { (calculated) }} / \mathrm{p}_{180 \text { (measured) }}$ by the gradual loss of the mass of the cylinder filling so that when the steady state was reached (i.e., $\mathrm{p}_{180 \text { (calculated) }}=\mathrm{p}_{180 \text { (measured) }}$ ) the calculated mass of the cylinder load was reduced by the measured props in the cranking mode under investigation. Thus, at a steady state, the state of $\Delta \mathrm{M}_{\text {blow in }} \cong \Delta \mathrm{M}_{\text {blow out }}$ will be balanced (the calculation allows some correction in the calculation settings for $\Delta \mathrm{M}_{\mathrm{blow}}$ in).

5. Thermal-technical modelling of the working cycles took place sequentially from cycle No. 0 so that after determining the pressure, the weight and temperature of the filling in BDC (after including the calculated mass of heat and profuse for the cycle, which was counted as single doses in BDC), the mass and pressure in $\mathrm{BDC}_{(180)}$ were inserted as input into the adjusted calculation program. The calculation of polytropic compression and expansion resulted in a temperature of $\mathrm{T}_{\mathrm{BDC}(540)}$, with which modelling of the next cycle began in the same process as in the previous cycle. An important quantity in working cycle modelling is determining the mean temperature of the walls in the cylinder. After a series of test calculations with different $\mathrm{T}_{\text {mean }}$ wall settings, $\mathrm{T}_{\text {mean wall }}=390 \mathrm{~K}$ (cycle No.0) was selected for the $3000 \mathrm{~min}^{-1}$ and $\mathrm{PPAR}_{\mathrm{P}}=6$ bar motoring mode, with a gradual increase up to $\mathrm{T}_{\text {mean wall }}=420 \mathrm{~K}$ in cycle No. 30 as a result of the calculations of incremental changes (till the cycle No. 200) in the cylinder workload (mass, pressure and temperature in $\mathrm{BDC}_{(180)}$ ) 
the calculated masses of the heat, blow-in and blow-out, IMEP_td-loss) (bar/cycle), $Q_{\text {heat transfer }}\left(\mathrm{J} / \mathrm{cycle}\right.$ ) and $\mathrm{p}_{\max (360)}(\mathrm{bar})$ were evaluated in each cycle. The runs of these quantities were plotted graphically and compared with the measurements taken in the appropriate motoring mode (mean values from statistical evaluation of data from the high-pressure indication and its thermodynamic analysis). Selected results are shown in Table 4, complete results are shown in Figure 22.

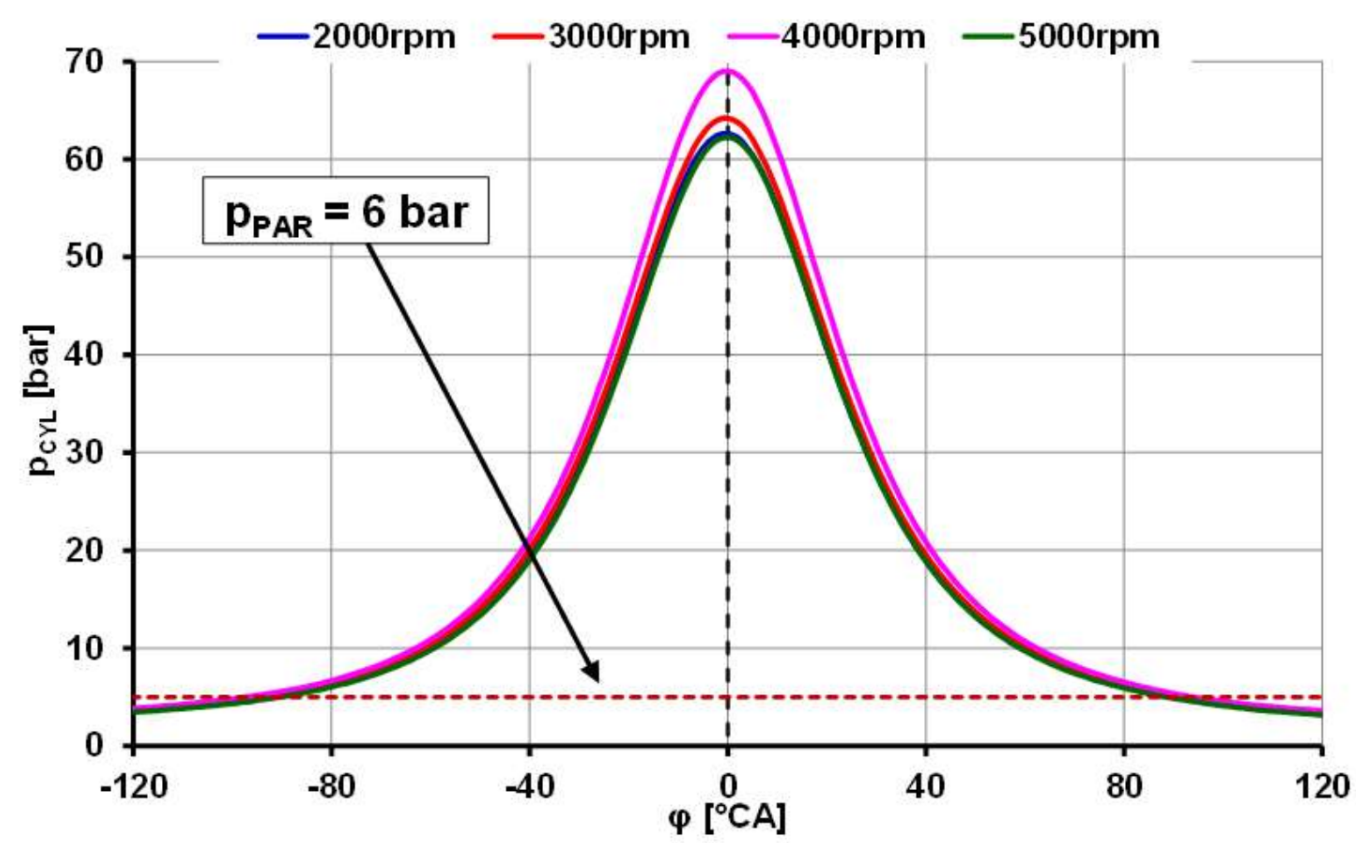

Figure 21. Cylinder pressure cycles when the engine was motored with the valves permanently closed, and the compressed air inlet pushed PPAR $=6$ bar to self-adjust valves. The change in PPAR settings only translated into pressure values. In terms of the $\Delta \varphi$ range for the self-operating valve function, the setting of other PPAR values was not significant.

Table 4. Selected results of the calculation of the incremental changes in the cylinder fill state according to Figure 22.

\begin{tabular}{ccc}
\hline \multirow{2}{*}{$\begin{array}{c}\text { Initial State in the Cylinder } \\
\text { (Estimated) }\end{array}$} & $\mathbf{p}_{\mathbf{1 8 0}}$ & $\mathbf{0 . 5 5} \mathbf{~ b a r}$ \\
\cline { 2 - 3 } & $\mathbf{M}_{\text {air }}$ & $\mathbf{0 . 3} \mathbf{~ g}$ \\
\hline Air Pressure Setting in the Rail & $\mathrm{p}_{\text {PAR }}$ & $6 \mathrm{bar}$ \\
\hline Steady State in the Cylinder After & 200 cycles & $4 \mathrm{~s}$ \\
\hline & $\mathrm{p}_{180}$ & $2.98 \mathrm{bar}$ \\
& $\mathrm{p}_{180 \text { (measured })}$ & $3.0 \mathrm{bar}$ \\
Monitored Quantities in Cycle no. 200 & $\mathrm{p}_{\text {max }}$ & $66 \mathrm{bar}$ \\
& $\mathrm{p}_{\max \text { average }}$ & $67.6 \mathrm{bar}$ \\
& $\mathrm{T}_{\text {BDC }(180)}$ & $272 \mathrm{~K}$ \\
& $\mathrm{M}_{\text {air }}$ & $1.69 \mathrm{~g}$ \\
& $\Delta \mathrm{M}_{\text {blow in }}$ & $0.004 \mathrm{~g} / \mathrm{cycle}$ \\
& $\Delta \mathrm{M}_{\text {blow out }}$ & $0.0036 \mathrm{~g} / \mathrm{cycle}$ \\
\hline
\end{tabular}


—T180 $[\mathrm{K}]-\mathrm{p} 180[\mathrm{bar}]$-M_cylinder $[\mathrm{g}]-\mathrm{M} \_$blow in $[\mathrm{g} \times 100]$

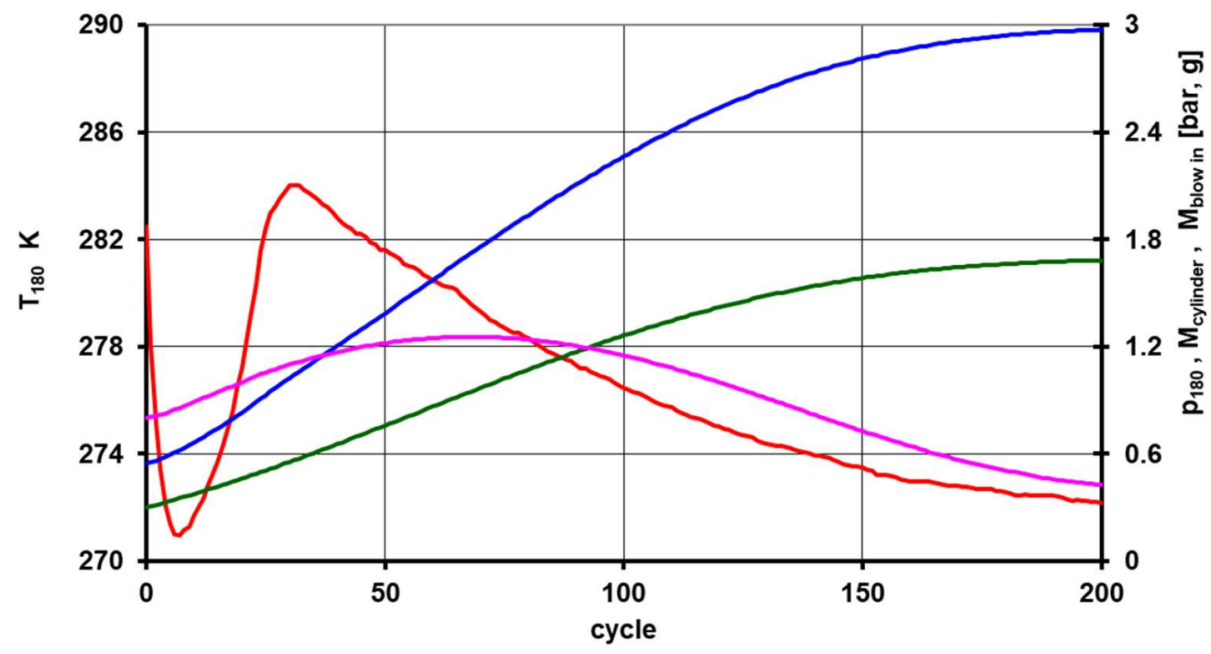

Figure 22. The result of calculating the successive changes in cylinder load state in BDC in cycles from the time of compressed air intake to the automatic valve in the $3000 \mathrm{~min}^{-1}$ modes and the pressure $\mathrm{p}_{\mathrm{PAR}}=6 \mathrm{bar}$.

The seemingly "strange" temperature course of $\mathrm{T}_{\mathrm{BDC}(180)}$ between cycles 0 and 30 resulted from several factors acting. Initially, the effect of heat transfer to the cylinder walls prevailed (see graph $Q_{\text {_heat transfer }}$ on Figure 23). The area of temperature increase was related to the gradual change in heat transfer and heat input by the air infused into the tiny air load of the cylinder. The sustained decrease in $\mathrm{T}_{\mathrm{BDC}(180)}$ resulted from

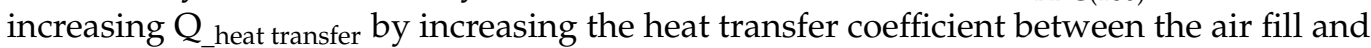
the cylinder walls.

The transfer of heat between the air filling and the cylinder walls was the integral result of the action of the heat transfer coefficient (functional dependence on the pressure and temperature of the air filling and other factors), the temperature drop between the air filling and the walls, the heat transfer area and time. Calculated heat transfer progress is shown Figure 23.

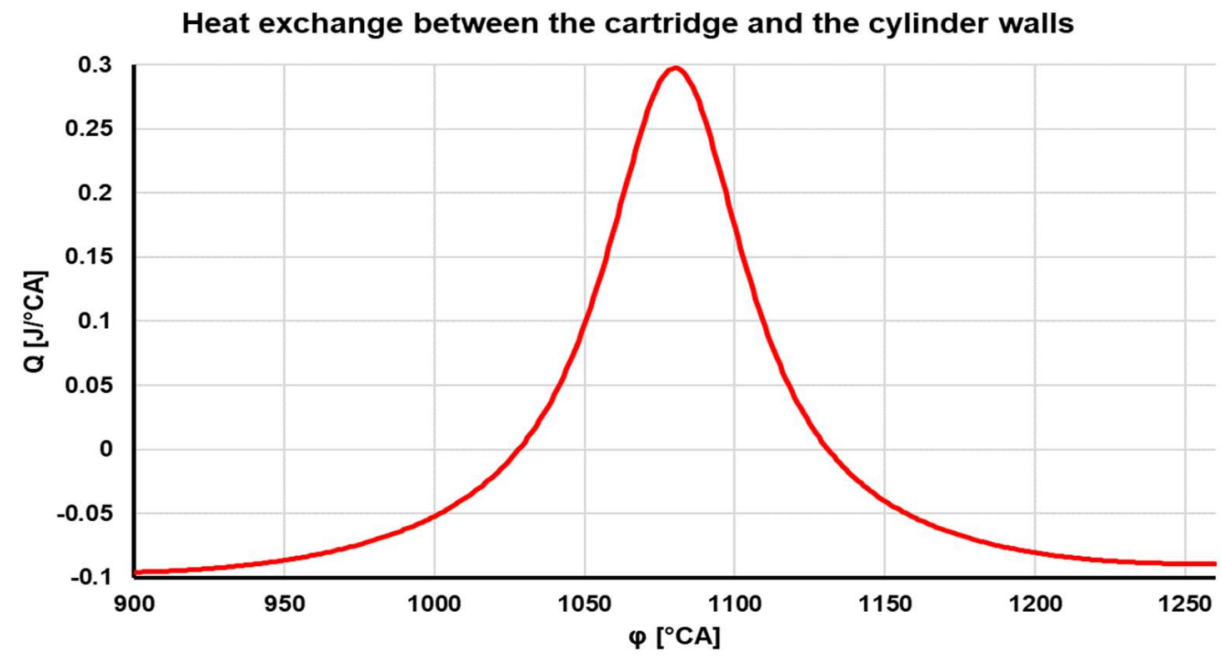

Figure 23. Changing the heat between the filling and the cylinder walls for cycle No 200.

The calculation result for cycle No 200 was $Q_{\text {heat transfer }}=-7 \mathrm{~J} /$ cycle. The calculation program was set to take heat from the filling into the walls, so the sign for the result means that the heat from the walls predominated over the cycle to the cylinder filling. At the same time, the graph shows that under engine conditions with permanently closed valves 
and calculation specifications (mean wall temperature of $420 \mathrm{~K}$ ), heat transferred from the charge to the walls in the $1030-1130^{\circ}$ position of CA $\left(100{ }^{\circ} \mathrm{CA}\right.$, i.e., about the last third of the piston stroke), the heating of the charge from the walls in the cylinder then proceeded to about $260^{\circ} \mathrm{CA}$. Transferring heat from the filling to the cylinder walls then affected another significant parameter of the working cycle, namely thermodynamic losses. Thermodynamic losses of IMEP_td-loss, which, together with the exchange of heat between the filling and the walls during the approach of the filling state in the cylinder to the steady-state, are shown in Figure 24.

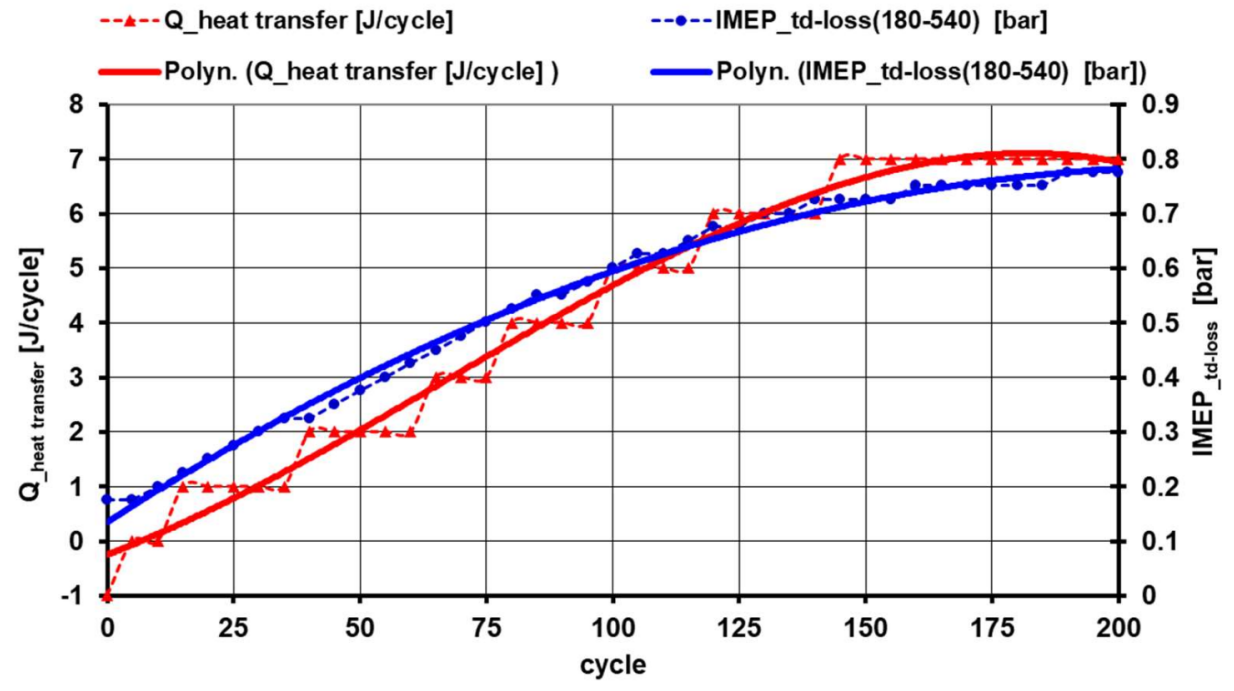

Figure 24. Thermodynamic losses of IMEP_td-loss, which, together with the exchange of heat between the filling and the walls, occured during the approach of the filling state in the cylinder to the steady-state.

The mean indicated vehicle rolling loss pressure with permanently closed valves logically increased with the gradual increase in the cylinder mass charge through the intake of compressed air doses and was also affected by the exchange of heat between the air fill and the cylinder walls. In cycle No. 200, the calculated value of IMEP_td-loss $=0.776$ bar. Evaluation of thermodynamic analysis of the high-pressure indication of the motored engine in the $5000 \mathrm{~min}^{-1}$ modes was carried out, and PPAR $=6$ bar was the mean value from statistical data processing of the indication of 200 duty cycles in all cylinders of the motored engine with permanently closed valves in the IMEP_td-loss_measured size $=0.698$ bar. Due to simplifications in thermal-technical calculations of the motoring engine cycles and some inaccuracies in determining the mean value from the IMEP_td-loss_measured measurement, the IMEP_td-loss from the calculated steady-state mode is in relatively good agreement with the measurement. This result can also be seen as a contribution to confirm the correctness of the calculation of the incremental state changes in the cylinder load of the engine with the valves permanently closed and the supply of compressed air doses to adjust the working pressure in the engine cylinder [12].

\section{Discussion}

New ways of measuring ICE mechanical losses by motoring are suitable tools for research and development of both ICE and piston rings, both in the scientific research field and especially in the automotive industry. From the results produced and the lessons learned from the experiments conducted, Option A may be considered a more appropriate way to investigate mechanical losses in the ICE and determine the dependence on engine cylinder pressure ratios. The measurement for Option B showed that the value of the mean indicated working pressure of the motoring engine is in good agreement. However, for this mode of motoring ICE, pulsations occurred in a relatively small volume of a closed circulation. Pulsations were induced by noncontinuous exhaust-side air inflows and 
noncontinuous intake-side air samples. They also affected the reliability of the measurement of the cylinder capacity exchange work (IMEPL) and thus the reliability of the determination of mechanical losses in the motored engine. The modification of the ICE for Option A, while resulting in significant interference with the functional state of the engine, is relatively simple and completely reversible.

Interestingly, Option A loads the piston group with twice the frequency of the standard four-stroke ICE. Option A can be used in accelerated wear tests on piston rings and research on friction loss in the piston group. An essential advantage of Option A with permanently closed valves is the lower energy intensity compared to motoring a fully functional closedcircuit engine. Calculated solutions of the state of the cylinder fill of a motoring engine with permanently closed valves showed a convincing way to change the state quantities of the cylinder fill and infuse the cylinder with a self-actuating valve for control of engine cylinder working pressures from PPAR pressure setting until engine operating mode was stabilised. The result is particularly interesting in terms of the air filling temperatures of the cylinder in the BDC, which can only be determined by calculation. The calculation methodology and result are a theoretical addition to the new method of experimental investigation of mechanical losses in a closed-circuit piston internal combustion engine and working pressures at the same level as those in a cylinder during regular engine operation.

\section{Conclusions}

Current methods of measuring the mechanical losses of reciprocating internal combustion engines by motoring make it possible to achieve a maximum of half the pressures in the engine cylinders compared to the pressures in the actual operation of the engine with the combustion of the fuel-air mixture. Lower pressures in the engine cylinders caused a significantly lower force load on the piston group and the crank mechanism. The measured mechanical losses in the engine cylinders were thus significantly distorted and far from reality. In the laboratories of the propulsion units of the Faculty of Mechanical Engineering of the Technical University in Liberec, research was carried out on new methods of measuring mechanical losses of a reciprocating internal combustion engine by motoring with pressure in the engine cylinders comparable to the pressures in the cylinders during standard operation of the combustion engine. The paper shows the results of measuring mechanical losses by motoring a reciprocating internal combustion engine in two new ways, including a comparison with the current classical motoring method. It explains the necessary adjustment of the engine for these measurements. The first new method involves not changing the cylinder charge and regulating the pressure in the cylinders by inserting compressed air with automatic valves into the cylinders of the motoring engine. The second new method is based on a closed working circuit connecting the exhaust with the intake. The filling pressure in the cylinders is set and maintained by a controlled supply of compressed air to the intake manifold. The first method proved to be a more suitable way to investigate mechanical losses in ICEs and determine the dependence of these losses on the pressure conditions in the engine cylinders. The paper also presented the results of a theoretical investigation for the state of the cylinder during the rotation of the ICE.

Author Contributions: Conceptualisation, R.P., A.D., R.V. and S.B.; methodology, R.P., A.D., R.V. and S.B.; data curation, R.P., A.D. and S.B.; validation, R.P., A.D. and S.B.; formal analysis, R.P., A.D. and S.B.; investigation, R.P., A.D. and S.B.; resources, R.P. and A.D.; draft preparation, R.P., A.D. and S.B.; writing-review and editing, R.P., A.D., R.V. and S.B.; visualisation, R.P. and A.D.; project administration, R.V.; funding acquisition, R.V. All authors have read and agreed to the published version of the manuscript.

Funding: This research was funded at the Technical University of Liberec as part of the project Center of Competence of the Automotive Industry Josef Božek TN01000026-1-WP02-017 with the support of the Specific University Research Grant, as provided by the Ministry of Education, Youth and Sports of the Czech Republic in 2021.

Institutional Review Board Statement: Not applicable. 
Informed Consent Statement: Not applicable.

Data Availability Statement: Not applicable.

Conflicts of Interest: The authors declare no conflict of interest.

\section{Abbreviations}

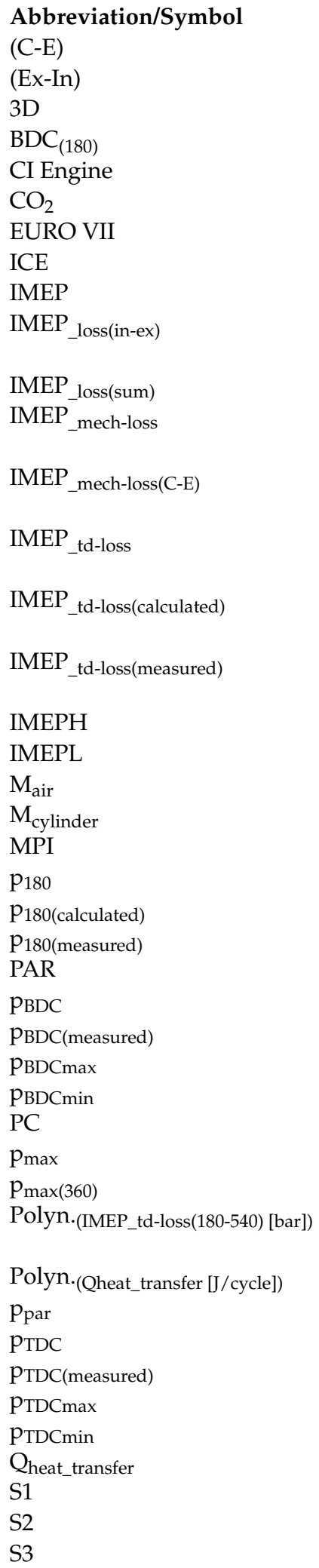

Description

Compression-expansion

Exhaust-Intake

Three-dimensional

Bottom dead centre

Compressed ignition engine

Carbon dioxide

European emission standard VII

Internal combustion engine

Indicated mean effective pressure

Indicated mean effective pressure loss of

cylinder volume exchange

Sum of loss indicated mean effective pressures

Indicated mean effective pressure of

mechanical losses

Indicated mean effective pressure of mechanical

losses for compression and expansion

Indicated mean effective pressure of

thermodynamic losses

Indicated mean effective pressure of thermodynamic losses-calculated

Indicated mean effective pressure of thermodynamic losses-measured

High-pressure part indicated mean effective pressure Low-pressure part indicated mean effective pressure Mass of air charge in the cylinder

The weight of the cylinder charge

Multipoint injection

Pressure for the initial cycle

Pressure for the initial cycle-calculated

Pressure for the initial cycle-measured

Pressured air reservoir

Bottom dead centre pressure

Maximum bottom dead centre pressure-measured

Maximum bottom dead centre pressure

Minimum bottom dead centre pressure

Personal computer

Maximum in-cylinder pressure

Maximum pressure for the entire operating cycle

Polynomic curve for indicated mean effective

pressure of thermodynamic losses

Polynomic curve for heat transfer

Pressure inside pressured air reservoir

Top dead centre pressure

Minimum top dead centre pressure-measured

Maximum top dead centre pressure

Minimum top dead centre pressure

Heat transfer

Output cross-section (with full plate stroke)

Cross-section

Cross-section [bar]

Unit

[bar]

[bar]

[bar]

[bar]

[bar]

[bar]

[bar]

[bar]

[bar]

[g]

[g]

[bar]

[bar]

[bar]

[bar]

[bar]

[bar]

[bar]

[bar]

[bar]

[J/cycle]

[J/cycle]

[bar]

[bar]

[bar]

[bar]

[bar]

[J/cycle]

$\left[\mathrm{mm}^{2}\right]$

$\left[\mathrm{mm}^{2}\right]$

$\left[\mathrm{mm}^{2}\right]$ 


$\begin{array}{lll}\text { SI Engine } & \text { Spark-ignition engine } & \\ \mathrm{S}_{\mathrm{RED} \_ \text {cross-section }} & \text { Reduced cross-section } & {\left[\mathrm{mm}^{2}\right]} \\ \mathrm{T}_{180} & \text { Temperature for the initial cycle } & {[\mathrm{bar}]} \\ \mathrm{T}_{\text {air_blow_in }} & \begin{array}{l}\text { Estimated temperature of the compressed air supplied } \\ \text { by the automatic valve to the cylinder }\end{array} & \\ & \text { Bottom dead centre for the initial cycle } & {[\mathrm{K}]} \\ \mathrm{T}_{\mathrm{BDC}(180)} & \text { Bottom dead centre temperature } & {[\mathrm{K}]} \\ \mathrm{T}_{\mathrm{BDC}(540)} & \text { Wall mean temperature } & {[\mathrm{K}]} \\ \mathrm{T}_{\text {mean_wall }} & \text { Torque loss } & {[\mathrm{K}]} \\ \mathrm{T}_{\mathrm{q} \_ \text {loss }} & \text { Pressure hose volume } & {\left[\mathrm{Nm}^{3}\right]} \\ \mathrm{V} 1 & \text { Volume of tube terminated by a self-closing plate valve } & {\left[\mathrm{mm}^{3}\right]} \\ \mathrm{V} 2 & {\left[\mathrm{~mm}^{3}\right]} \\ \mathrm{V} 3 & \text { Sum of volumes V1 and V2 } & {\left[\mathrm{mm}^{3}\right]} \\ \left.\Delta \mathrm{M}_{\text {blow_in }}\right] & \text { Mass of blow-in } & {[\mathrm{g} / \mathrm{cycle}]} \\ \Delta \mathrm{M}_{\text {blow_out }} & \text { Mass of blow-out } & {[\mathrm{g} / \mathrm{cycle}]} \\ \Delta \varphi & \text { Crankshaft rotation range } & {\left[{ }^{\circ} \mathrm{CA}\right]}\end{array}$

\section{References}

1. Beroun, S.; Páv, K. Selected Topics of Vehicle Combustion Engines, 1st ed.; TU Liberec: Liberec, Czech Republic, 2017; p. 149, ISBN 978-80-7372-957-8.

2. $\quad$ Beroun, S.; Voženílek, R. Measurement of Passive Engine Resistances (Complete Engine and Its Selected Groups) by Cranking. Research Report DVE 617/2009; TU Liberec: Liberec, Czech Republic, 2009; p. 13.

3. Procházka, R.; Dittrich, A. TN01000026-1-WP02-007 Measuring mechanical losses of piston combustion engine by spinning at various working pressures in engine cylinders. In Proceedings of the M2D2019 8th International Conference Mechanics and Materials in Design, Bologna, Italy, 4-6 September 2019; Società Editrice Esculapio: Bologna, Italy, 2019; pp. 65-66.

4. Voženílek, R.; Beroun, S.; Dittrich, A. Measuring the passive resistance of the piston combustion engine by cranking with increase pressure in cylinder. In Proceedings of the XLVIII International Scientific Conference of Czech and Slovak University Departments and Institutions Dealing with the Research of Combustion Engines, Liberec, Czech Republic, 11-12 September 2017; pp. 191-198, ISBN 978-80-7494-354-6.

5. Novotný, P.; Pištěk, V.; Drapál, L. Modelling of Piston Ring Pack Dynamics; Journal MECCA IX/02; Czech Technical University in Prague: Prague, Czech Republic, 2011; pp. 8-12, ISSN 1214-0821.

6. Hopfner, W.; Lösch, S.; Satschen, S.; Winklhofer, E. Friction test procedures in engine development. In Proceedings of the Conference: 5. Tribologie und Effizienztagung, Györ, Hungary, 19-20 June 2018. Available online: https: / / www.researchgate. net/publication/328723117_Friction_test_procedures_in_engine_development/stats (accessed on 8 December 2021).

7. Knauder, C.; Allmaier, H.; Sander, D.E.; Sams, T. Investigations of the Friction Losses of Different Engine Concepts. Part 1: A Combined Approach for Applying Subassembly-Resolved Friction Loss Analysis on a Modern Passenger-Car Diesel Engine. Lubricants 2019, 7, 39. [CrossRef]

8. Knauder, C.; Allmaier, H.; Sander, D.E.; Sams, T. Investigations of the Friction Losses of Different Engine Concepts. Part 2: Sub-Assembly Resolved Friction Loss Comparison of Three Engines. Lubricants 2019, 7, 105. [CrossRef]

9. Allmaier, H.; Knauder, C.; Salhofer, S.; Reich, F.; Schalk, E.; Ofner, H.; Wagner, A. An experimental study of the load and heat influence from combustion on engine friction. Int. J. Engine Res. 2015, 17, 347-353. [CrossRef]

10. Voženílek, R.; Beroun, S.; Procházka, R. New Method of Measuring Mechanical Losses by Motoring of Internal Combustion Engine. In Proceedings of the 51th International Scientific Conference of Czech and Slovak University Departments and Institutions Dealing with the Research of Internal Combustion Engines, CTU Prague, Czech Republic, 9-10 September 2020; pp. 60-69, ISBN 978-80-01-06744-4.

11. Mikulanin, L.; Dittrich, A.; Dráb, O. Measurement of the Passive Resistance of the 1.6 MPI Engine at the Spinning Station; TU Liberec: Liberec, Czech Republic, 2015; Unpublished DVE Working Document.

12. Beroun, S. The State of the Cylinder Filling when Motoring the ICE without Replacing the Filling and Controlled Air Supply for Increasing Pressure; TU Liberec: Liberec, Czech Republic, 2020; Research Report DVE. 